\title{
How to schedule VEGF and PD-1 inhibitors in combination cancer therapy?
}

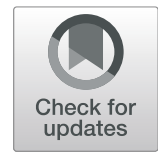

Xiulan Lai ${ }^{1}$ and Avner Friedman ${ }^{2 *}$

\begin{abstract}
Background: One of the questions in the design of cancer clinical trials with combination of two drugs is in which order to administer the drugs. This is an important question, especially in the case where one agent may interfere with the effectiveness of the other agent.

Results: In the present paper we develop a mathematical model to address this scheduling question in a specific case where one of the drugs is anti-VEGF, which is known to affect the perfusion of other drugs. As a second drug we take anti-PD-1. Both drugs are known to increase the activation of anticancer T cells. Our simulations show that in the case where anti-VEGF reduces the perfusion, a non-overlapping schedule is significantly more effective than a simultaneous injection of the two drugs, and it is somewhat more beneficial to inject anti-PD-1 first.

Conclusion: The method and results of the paper can be extended to other combinations, and they could play an important role in the design of clinical trials with combination therapy, where scheduling strategies may significantly affect the outcome.
\end{abstract}

Keywords: Anti-PD-1, Anti-VEGF, Combination therapy, Scheduling, PDE model

\section{Background}

Anti-vascular endothelial growth factor (anti-VEGF) is a drug commonly used as anticancer agent, although numerous studies show only modest results [1]. In combination with chemotherapy anti-VEGF improves anticancer therapy, although the outcome depends on the cancer type and on the scheduling of the treatment [2]. The scheduling issue arises from the fact that antiVEGF decreases perfusion of chemotoxic agents in some cancers, including melanoma [3], breast cancer [4, 5] and ovarian cancer [6], while it increases perfusion of chemotoxic agents in other cancers, such as colon cancer $[7,8]$ and head and neck cancer [9]. More recently Asrid et al [10] reported a rapid decrease in the delivery of chemotherapy to the tumor in patients of non-small cell lung cancer (NSCLC) after anti-VEGF therapy, highlighting the importance of drug scheduling in combination therapy when anti-VEGF is one of the drugs.

*Correspondence: afriedman@math.osu.edu

${ }^{2}$ Mathematical Bioscience Institute \& Department of Mathematics, Ohio State University, Columbus, $\mathrm{OH}$, USA

Full list of author information is available at the end of the article
Less than $4 \%$ of positive phase II cancer clinical trials with combination chemotherapy demonstrate improvement of care in phase III [11]. Hence, the decision to go from phase II to phase III needs to identify more effectively which combinations will have a higher probability of success in phase III [12]. It was suggested in [13] that the design of clinical trials with combination therapy should be based, among other factors, on the scientific rationale underlying data and hypothesis for the combination.

In a previous work [14] we considered a combination therapy with a checkpoint inhibitor and cancer vaccine, and explored the synergy between the two drugs, taking into account potential negative side effects. In another paper [15] we considered the combination of BRAF/MEK inhibitor and checkpoint inhibitor, and showed that although the two drugs are positively correlated for most combinations of the doses, there is an exceptional range of doses where the two drugs are mutually antagonistic.

In the present paper we consider a combination therapy of anti-VEGF and a checkpoint inhibitor, and focus on the scheduling issue of these drugs. The rationale for using such a combination originates from the fact that VEGF impairs the function of anti-cancer T cells [16-20]; hence VEGF inhibition will enhance $T$ cells function, and 
checkpoint blockade could therefore significantly advance antitumor therapy. The anticancer synergy between antiVEGF and checkpoint inhibitors is currently being evaluated in clinical trials in renal cancer [21,22].

In the case where anti-VEGF therapy decreases the perfusion of a second antitumor agent, the following question arises [23, 24]: Should the treatment with combination of anti-VEGF and a checkpoint inhibitor be given at the same time, or is it more beneficial to delay treatment of one of the two drugs, so that they are given non-overlappingly?

To address this question we develop a mathematical model using a system of partial differential equations (PDEs). The variables of the model include CD4+ (Th1) and $\mathrm{CD}^{+} \mathrm{T}$ cells, regulatory $\mathrm{T}$ cells (Tregs), dendritic cells (DCs), endothelial cells, and cancer cells. The model also includes VEGF and TGF- $\beta$ produced by cancer cells, and cytokines IL-12 and IL-2. The network of interactions among these species is shown in Fig. 1. This figure includes also oxygen concentration, and programmed cell death protein 1 (PD-1) and its ligand PD-L1. As indicated in Fig. 1. VEGF impairs the maturation of (antigenpresenting) dendritic cells [25, 26], and it suppresses the functions of activated $\mathrm{T}$ cells [16-20]; VEGF also enhances the expression of PD- 1 on $\mathrm{CD}^{+} \mathrm{T}$ cells [27], and induces Treg proliferation [28].

The mathematical model is based on the network shown in Fig. 1. The basic assumption in the model is that antiVEGF decreases the perfusion of anti-PD-1 in the tumor microenvironment as in the case in melanoma, breast cancer, and ovarian cancer. The range of the injected amounts of drugs in the model was chosen so that the simulations will be in agreement with experimental results in mice models [27, 29].

We can use the model to assess the efficacy of the combination therapy when the treatment with anti-VEGF is delayed or advanced relative to anti-PD-1, for different schedules if treatment. In particular we show that the treatment is significantly more effective if instead of administering the two drugs at the same time, we administer them non-overlappingly.

We finally consider briefly the case where anti-VEGF increases the perfusion of anti-PD-1, and show that in this case there are more benefits when the two drugs are given simultaneously.

\section{Methods}

\section{Mathematical model}

The mathematical model is based on the network shown in Fig. 1. The list of variables is given in Table 1.

We assume that the total density of cells within the tumor remains constant throughout the tumor tissue, for all time:

$$
D+T_{1}+T_{8}+T_{r}+E+C=\text { constant, }
$$

and that the density of debris of dead cells is also constant. We further assume that the densities of immature dendritic cells, and of naive $\mathrm{CD} 4^{+}$and $\mathrm{CD} 8^{+} \mathrm{T}$ cells, remain constant throughout the tumor tissue. As cancer cells proliferate, they "push away," or displace, other cells. There is

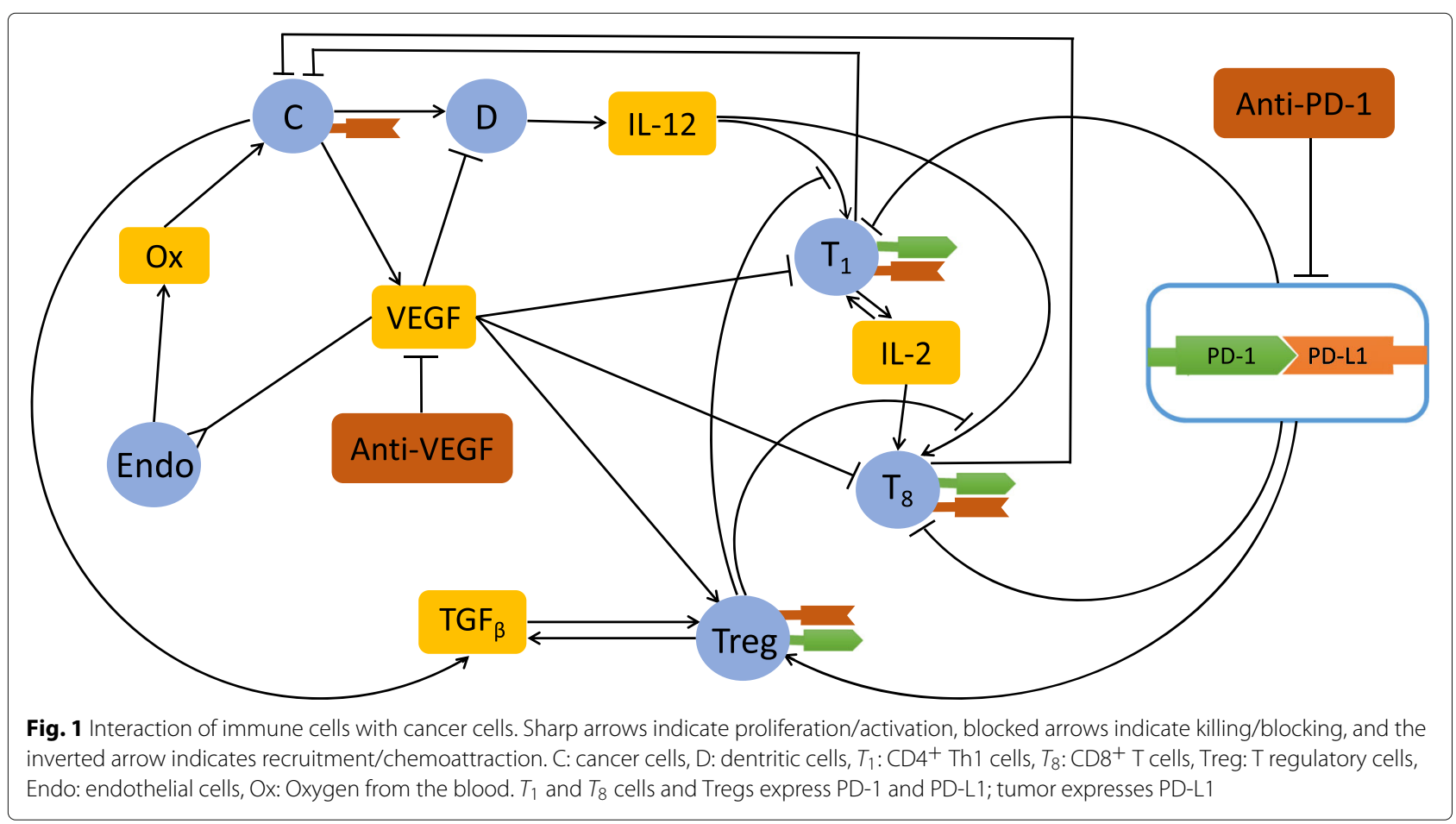


Table 1 List of variables (in units of $\mathrm{g} / \mathrm{cm}^{3}$ )

\begin{tabular}{ll}
\hline Notation & Description \\
\hline$D$ & density of dendritic cells \\
$T_{1}$ & density of activated CD4 ${ }^{+}$T cells \\
$T_{8}$ & density of activated CD8 ${ }^{+} T$ cells \\
$T_{r}$ & density of activated Treg cells \\
$E$ & density of endothelial cells \\
$C$ & density of cancer cells \\
$N_{C}$ & density of necrotic cell \\
$H$ & HMGB-1 concentration \\
$I_{12}$ & IL-12 concentration \\
$I_{2}$ & IL-2 concentration \\
$T_{\beta}$ & TGF- $\beta$ concentration \\
$W$ & oxygen concentration \\
$G$ & VEGF concentration \\
$P_{1}$ & concentration of PD-1 on CD4 ${ }^{+}$T cells \\
$P_{8}$ & concentration of PD-1 on CD8 ${ }^{+}$T cells \\
$L$ & PD-L1 concentration \\
$Q$ & PD-1-PD-L1 concentration \\
$A$ & anti-PD-L1 concentration \\
$B$ & anti-VEGF concentration \\
\hline &
\end{tabular}

also migration of endothelial cells and immune cells into the tumor. Since the total density of cells was assumed to be constant at each point and time, by Eq.(1), these increases in the population of cells create a pressure $(p)$ among the cells with an associated velocity field $\mathbf{u}$. Under some additional assumptions on the material structure of the tumor, one can actually connect $\mathbf{u}$ to $p$ (for example, by Darcy's law in porous media), but we shall not need to do this in our model. The vector $\mathbf{u}$ is a function of space and time, taken in units of $\mathrm{cm} /$ day.

We also assume that all the cytokines and anti-tumor drugs are diffusing within the tumor tissue, and that also the cells are undergoing diffusion (i.e. dispersion), although with much smaller coefficients.

Although in our model we use densities of cells, it is interestingly to visualize how individual cells interact within the tumor. Figure 2 displays a distribution of cells in space, based on Fig. 1. We note, in particular, that cancer cells move toward the tumor boundary where the oxygen level can supports their abnormal proliferation; hence, by Eq. (1), the other types of cells are "pushed" toward the tumor core.

\section{Equation for $D C s(D)$}

By necrotic cancer cells $\left(N_{C}\right)$ we mean cancer cells undergoing the process of necrosis. Necrotic cancer cells release high mobility group box 1 protein (HMGB-1) [30]. We model the dynamics of $N_{C}$ and HMGB-1 $(H)$ by the following equations:

$$
\begin{aligned}
& \frac{\partial N_{C}}{\partial t}+\underbrace{\nabla \cdot\left(\mathbf{u} N_{C}\right)}_{\text {velocity }}-\underbrace{\delta_{N_{C}} \nabla^{2} N_{C}}_{\text {difusion }}=\underbrace{\lambda_{N_{C} C} C}_{\text {derived from life cancer cells }}-\underbrace{d_{N_{C} N_{C}}}_{\text {removal }}, \\
& \frac{\partial H}{\partial t}-\underbrace{\delta_{H} \nabla^{2} H}_{\text {difusion }}=\underbrace{\lambda_{H N_{C} N_{C}}}_{\text {released from nerotic cancer cells }}-\underbrace{d_{H} H,}_{\text {degradation }}
\end{aligned}
$$

where $\lambda_{N_{C} C}$ is the rate of cancer cells becoming necrotic and $\lambda_{H N_{C}}$ is the production rate of HMGB-1 by necrotic cells. We note that since molecules like HMGB-1, or other proteins, are several orders of magnitude smaller than

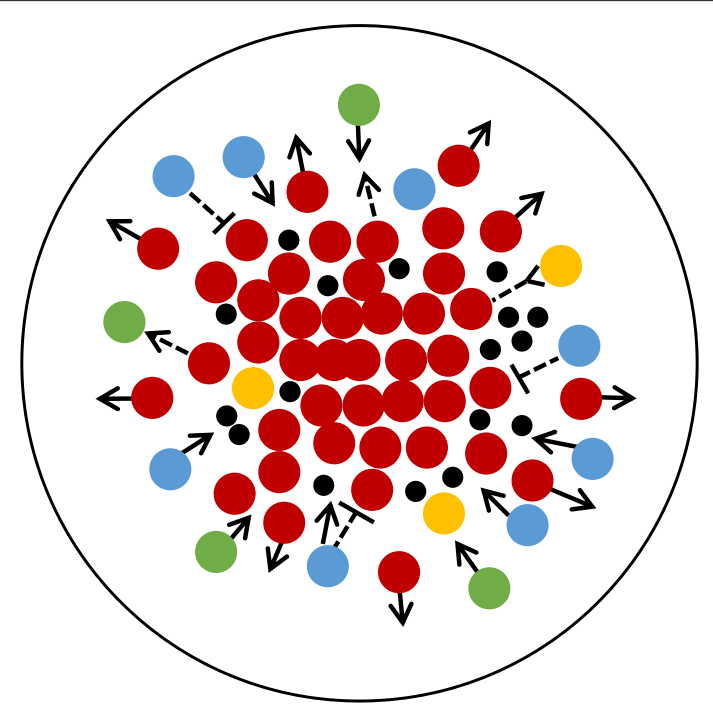

Cancer cell

$\mathrm{T} 1$ or $\mathrm{T} 8$ cell

Dendritic cell

Endothelial cell

- VEGF

$\rightarrow$ Activation

--j Killing

---< Attraction

$\rightarrow$ Movement

Fig. 2 Distribution of cells in space 
cells, their diffusion coefficients are several orders of magnitude larger than the diffusion coefficients of cells, and they are only marginally influenced by the cells velocity $\mathbf{u}$, so we do not include a velocity term in their equations. The degradation of HMGB-1 is fast ( $\sim 0.01 /$ day) [31], and we assume that the process of necrosis is also fast. We may then approximate the two dynamical equations by the steady state equations $\lambda_{N_{C} C} C-d_{N_{C}} N_{C}=0$ and $\lambda_{H N_{C}} N_{C}-d_{H} H=0$, so that $H$ is proportional to $C$.

Dendritic cells are activated by HMGB-1 [32, 33]. Hence, the activation rate of immature dendritic cells, with density $D_{0}$, is proportional to $D_{0} \frac{H}{K_{H}+H}$, or to $D_{0} \frac{C}{K_{C}+C}$. Here, the Michaelis-Menten law was used to account for the limited rate of receptor recycling which takes place in the process of DCs activation. The dynamics of DCs is given by the following equation:

$$
\frac{\partial D}{\partial t}+\underbrace{\nabla \cdot(\mathbf{u} D)}_{\text {velocity }}-\underbrace{\delta_{D} \nabla^{2} D}_{\text {difusion }}=\underbrace{\lambda_{D C} D_{0} \frac{C}{K_{C}+C}}_{\text {activation by HMGB-1 }} \cdot \underbrace{\frac{1}{1+G / K_{D G}}}_{\text {inhibition by VEGF }}-\underbrace{d_{D} D,}_{\text {death }}
$$

where $\delta_{D}$ is the diffusion coefficient, $d_{D}$ is the death rate of DCs, and $1 /\left(1+G / K_{D G}\right)$ represents the impairment of maturation of dendritic cells by VEGF $[25,26]$.

\section{Equations for $\mathrm{CD}^{+} T$ cells $\left(T_{1}\right)$ and $\mathrm{CD} 8^{+} T$ cells $\left(T_{8}\right)$}

Naive CD4 ${ }^{+} \mathrm{T}$ cells differentiate into active Th1 cells $\left(T_{1}\right)$ under IL-12 $\left(I_{12}\right)$ environment $[34,35]$, and this process is inhibited by Tregs $[36,37]$ and by VEGF [16-20]. The proliferation of activated $T_{1}$ cells is enhanced by IL- 2 . Both processes of activation and proliferation of $T_{1}$ are assumed to be inhibited by PD-1-PD-L1 (Q) [38, 39]; we represent this inhibition by the factor $\frac{1}{1+Q / K_{T Q}}$. Hence $T_{1}$ satisfies the following equation:

$$
\begin{aligned}
\frac{\partial T_{1}}{\partial t}+ & \nabla \cdot\left(\mathbf{u} T_{1}\right)-\delta_{T} \nabla^{2} T_{1} \\
& =\underbrace{\left(\lambda_{T_{1} I_{12}} T_{10} \cdot \frac{I_{12}}{K_{I_{12}}+I_{12}}\right.}_{\text {activation by IL-12 }} \cdot \underbrace{\frac{1}{1+T_{r} / K_{T T_{r}}}}_{\text {inhibition by Tregs }} \cdot \underbrace{\frac{1}{1+G / K_{T G}}}_{\text {inhibition by VEGF }} \\
+ & \underbrace{\left.\lambda_{T_{1} I_{2}} T_{1} \frac{I_{2}}{K_{I_{2}}+I_{2}}\right)}_{\text {IL-2-induced proliferation }} \times \underbrace{\frac{1}{1+Q / K_{T Q}}}_{\text {inhibition by PD-1-PD-L1 }}-\underbrace{d_{T_{1} T_{1}}}_{\text {death }}
\end{aligned}
$$

where $T_{10}$ is the density of the naive $\mathrm{CD} 4^{+} \mathrm{T}$ cells.

Similarly, inactive CD8 ${ }^{+} \mathrm{T}$ cells are activated by IL-12 $[34,35]$, a process resisted by Tregs $[36,37]$ and VEGF [16-20], while IL-2 enhances the proliferation of activated $\mathrm{CD}^{+}{ }^{+} \mathrm{T}$ cells. Hence,

$$
\begin{aligned}
\frac{\partial T_{8}}{\partial t}+ & \nabla \cdot\left(\mathbf{u} T_{8}\right)-\delta_{T} \nabla^{2} T_{8} \\
& =\underbrace{\left(\lambda_{T_{8} I_{12}} T_{80} \cdot \frac{I_{12}}{K_{I_{12}}+I_{12}}\right.}_{\text {activation by IL-12 }} \cdot \underbrace{\frac{1}{1+T_{r} / K_{T T_{r}}}}_{\text {inhibition by Tregs }} \cdot \underbrace{\frac{1}{1+G / K_{T G}}}_{\text {inhibition by VEGF }} \\
& +\underbrace{\left.\lambda_{T_{8} I_{2}} T_{8} \frac{I_{2}}{K_{I_{2}}+I_{2}}\right)}_{\text {IL-2-induced proliferation }} \times \underbrace{\frac{1}{1+Q / K_{T Q}}}_{\text {inhibition by PD-1-PD-L1 }}-\underbrace{d_{T_{8}} T_{8}}_{\text {death }},
\end{aligned}
$$

where $T_{80}$ is the density of the inactive $\mathrm{CD} 8^{+} \mathrm{T}$ cells.

\section{Equation for Tregs $\left(T_{r}\right)$}

Naive $\mathrm{CD}^{+}{ }^{+} \mathrm{T}$ cells differentiate into $T_{r}$ cells under the influence of TGF- $\beta$ : $\left(T_{\beta}\right)[37,40]$ and VEGF [28]. The equation for $T_{r}$ takes the following form:

$$
\begin{aligned}
& \frac{\partial T_{r}}{\partial t}+\nabla \cdot\left(\mathbf{u} T_{r}\right)-\delta_{T} \nabla^{2} T_{r}=T_{10} \quad\left(\lambda_{T_{r} T_{\beta}} \frac{T_{\beta}}{K_{T_{\beta}}+T_{\beta}}\right. \\
& \text { TGF- } \beta \text {-induced proliferation } \\
& +\underbrace{\left.\lambda_{T_{r} G} \frac{G}{K_{G}+G}\right)}_{\text {promotion by VEGF }}-\underbrace{d_{T_{r}} T_{r}}_{\text {death }} .
\end{aligned}
$$

\section{Equation for endothelial cells (E)}

Endothelial cells are chemoattracted by VEGF, and their proliferation is increased by VEGF $[41,42]$. The equation for the density of endothelial cells is given by

$$
\begin{aligned}
\frac{\partial E}{\partial t}+\nabla \cdot(\mathbf{u} E)-\delta_{E} \nabla^{2} E= & \underbrace{\lambda_{E}(G) E\left(1-\frac{E}{E_{M}}\right)}_{\text {proliferation }} \\
& -\underbrace{\nabla \cdot\left(\chi_{G} E \nabla G\right)}_{\text {recruited by VEGF }}-\underbrace{d_{E} E,}_{\text {death }}
\end{aligned}
$$

where $E_{M}$ is the carrying capacity of endothelial cells, $\lambda_{E}(G)=\lambda_{E G}\left(G-G_{0}\right)^{+}$, and $G_{0}$ is a threshold below which endothelial cells do not proliferate [43]. Here we used the notion: $X^{+}=X$ if $X \geq 0$ and $X^{+}=0$ if $X<0$.

\section{Equation for cancer cells (C)}

We assume a logistic growth for cancer cells, with carrying capacity $\left(C_{M}\right)$, in order to account for competition for space among these cells. The proliferation rate depends on the density of oxygen $(W)$ [42]. The equation for $C$ takes the following form:

$$
\begin{aligned}
\frac{\partial C}{\partial t}+\nabla \cdot(\mathbf{u} C)-\delta_{C} \nabla^{2} C= & \underbrace{\lambda_{C}(W) C\left(1-\frac{C}{C_{M}}\right)}_{\text {proliferation }} \\
& -\underbrace{\eta_{1} T_{1} C-\eta_{8} T_{8} C}_{\text {killing by T cells }}-\underbrace{d_{C} C}_{\text {death }},
\end{aligned}
$$


where $\eta_{1}$ and $\eta_{8}$ are the killing rates of cancer cells by $T_{1}$ and $T_{8}$ cells, respectively. $d_{C}$ is the natural death rate of cancer cells, and

$$
\lambda_{C}(W)= \begin{cases}\lambda_{C W} \frac{W}{W_{0}} & \text { if } W \leq W_{0} \\ \lambda_{C W} & \text { if } W>W_{0},\end{cases}
$$

where $W_{0}$ is the normal level of oxygen concentration in the blood.

\section{Equation for IL-12 (I12)}

The proinflammatory cytokine IL-12 is secreted by activated DCs [34, 35]; hence it satisfies the equation:

$$
\frac{\partial I_{12}}{\partial t}-\delta_{I_{12}} \nabla^{2} I_{12}=\underbrace{\lambda_{I_{12} D} D}_{\text {production by DCs }}-\underbrace{d_{I_{12}} I_{12} .}_{\text {degradation }}
$$

\section{Equation for IL-2 ( $\left.I_{2}\right)$}

IL-2 is produced by activated CD4 ${ }^{+} \mathrm{T}$ cells $\left(T_{1}\right)$ [35]. Hence,

$$
\frac{\partial I_{2}}{\partial t}-\delta_{I_{2}} \nabla^{2} I_{2}=\underbrace{\lambda_{I_{2} T_{1} T_{1}}}_{\text {production by } T_{1}}-\underbrace{d_{I_{2} I_{2}}}_{\text {degradation }}
$$

\section{Equation for TGF- $\beta$ : $\left(T_{\beta}\right)$}

TGF- $\beta$ is produced by tumor cells [36] and Tregs [37], so that

$$
\begin{aligned}
\frac{\partial T_{\beta}}{\partial t}-\delta_{T_{\beta}} \nabla^{2} T_{\beta}= & \underbrace{}_{\begin{array}{c}
\text { production by cancer cells } \\
\lambda_{T_{\beta} C} C
\end{array}} \\
& +\underbrace{\lambda_{T_{\beta} T_{r} T_{r}}}_{\text {production by Tregs }}-\underbrace{d_{T_{\beta} T_{\beta}}}_{\text {degradation }} .
\end{aligned}
$$

\section{Equation for oxygen (W)}

Oxygen is infused through the blood [41, 42]. We identify the blood concentration with the density of endothelial cells and, accordingly, write the equation for $W$ in the following form:

$$
\frac{\partial W}{\partial t}-\delta_{W} \nabla^{2} W=\underbrace{\lambda_{W E} E}_{\text {source from blood }}-\underbrace{d_{W} W,}_{\text {consumption by cells }}
$$

where $d_{W} W$ represents the take-up rate of oxygen by all the cells.

\section{Equation for VEGF (G)}

VEGF is produced by cancer cells $[41,42]$ and is depleted by anti-VEGF. Hence $G$ satisfies the following equation:

$$
\begin{aligned}
\frac{\partial G}{\partial t}-\delta_{G} \nabla^{2} G= & \underbrace{\lambda_{G}(W) C}_{\text {production by cancer cells }}-\underbrace{\mu_{G B} G B}_{\text {inhibition by anti-VEGF }} \\
& -\underbrace{d_{G} G}_{\text {degradation }},
\end{aligned}
$$

where $B$ is the effective anti-VEGF concentration in the tumor, and

$$
\lambda_{G}(W)=\lambda_{G W} \times \begin{cases}\frac{W}{W^{*}} & \text { if } 0 \leq W \leq W^{*} \\ 1-0.7 \frac{W-W^{*}}{W_{0}-W^{*}} & \text { if } W^{*}<W \leq W_{0} \\ 0.3 & \text { if } W>W_{0} .\end{cases}
$$

Here we assumed that the secretion rate of VEGF by cancer cells increases with the oxygen level, but falls off when oxygen level exceeds a certain level, $W^{*}[44]$.

\section{Equations for PD-1 (P), PD-L1 (L) and PD-1-PD-L1 (Q)}

PD-1 is expressed on the surface of activated CD4 ${ }^{+} \mathrm{T}$ cells, activated $\mathrm{CD}^{+} \mathrm{T}$ cells, and Tregs $[38,45]$. We assume that the number of $\mathrm{PD}-1$ receptors per cell is the same for $T_{1}$ and $T_{8}$ cells, but is smaller, by a factor $\varepsilon_{T}$, for $T_{r}$ cells. VEGF increases the PD- 1 on $T_{8}$ cells by a factor $\varepsilon_{G} G$ [27]. If we denote by $\rho_{P}$ the ratio between the mass of one PD-1 protein to the mass of one $\mathrm{T}$ cell, then the total concentration of PD-1 on $T_{1}$ and $T_{r}$ cells is given by

$$
P_{1}=\rho_{P}\left(T_{1}+\varepsilon_{T} T_{r}\right)
$$

and the concentration of PD- 1 on $T_{8}$ cells is given by

$$
P_{8}=\rho_{P} T_{8}\left(1+\varepsilon_{G} G\right) .
$$

PD-L1 is expressed on activated CD4 ${ }^{+}$T cells, activated $\mathrm{CD}^{+} \mathrm{T}$ cells [38], Tregs [46], and cancer cells [38, 39]. We assume that the number of PD-L1 per cell is the same for $T_{1}$ and $T_{8}$ cells, and denote the ratio between the mass of one PD-L1 protein to the mass of one cell by $\rho_{L}$. Then

$$
L=\rho_{L}\left(T_{1}+T_{8}+\varepsilon_{T} T_{r}+\varepsilon_{C} C\right),
$$

for some parameters $\varepsilon_{T}$, $\varepsilon_{C}$, where $\varepsilon_{C}$ depends on the specific type of tumor.

To a change in $T=T_{1}+\varepsilon_{T} T_{r}$, given by $\frac{\partial T}{\partial t}$, there corresponds a change of $P_{1}$, given by $\rho_{P} \frac{\partial T}{\partial t}$. For the same reason, $\nabla \cdot\left(\mathbf{u} P_{1}\right)=\rho_{P} \nabla \cdot(\mathbf{u} T)$ and $\nabla^{2} P_{1}=\rho_{P} \nabla^{2} T$ when no anti-PD-1 drug is injected. Hence, $P_{1}$ satisfies the following equation:

$$
\begin{aligned}
\frac{\partial P_{1}}{\partial t}+\nabla \cdot\left(\mathbf{u} P_{1}\right)-\delta_{T} \nabla^{2} P_{1}= & \rho_{P} \\
& {\left[\frac{\partial\left(T_{1}+\varepsilon_{T} T_{r}\right)}{\partial t}\right.} \\
& +\nabla \cdot\left(\mathbf{u}\left(T_{1}+\varepsilon_{T} T_{r}\right)\right) \\
& \left.-\delta_{T} \nabla^{2}\left(T_{1}+\varepsilon_{T} T_{r}\right)\right] .
\end{aligned}
$$

Recalling Eqs. (3) and (5) for $T_{1}$ and $T_{r}$, we get,

$$
\begin{aligned}
\frac{\partial P_{1}}{\partial t}+ & \nabla \cdot\left(\mathbf{u} P_{1}\right)-\delta_{T} \nabla^{2} P_{1} \\
& =\rho_{P}\left[\text { RHS of Eq. (3) }+\varepsilon_{T}, \times \text { RHS of Eq. (5) }\right]
\end{aligned}
$$


where RHS=right-hand side. Similarly,

$$
\begin{aligned}
\frac{\partial P_{8}}{\partial t}+ & \nabla \cdot\left(\mathbf{u} P_{8}\right)-\delta_{T} \nabla^{2} P_{8} \\
& =\rho_{P}\left[\left(1+\varepsilon_{G} G\right) \times \text { RHS of Eq. }(4)+\varepsilon_{G} T_{8} \times\right. \text { RHS of Eq. (12) } \\
& \left.+\varepsilon_{G} T_{8} \nabla \cdot \mathbf{u} G+\varepsilon_{G}\left(\delta_{G}-\delta_{T}\right) T_{8} \nabla^{2} G-2 \varepsilon_{G} \delta_{T} \nabla T_{8} \cdot \nabla G\right] .
\end{aligned}
$$

When only anti-PD-1 drug $(A)$ is injected, PD-1 is depleted at a rate $\mu_{P A} P_{1} A$, but when also anti-VEGF $(B)$ is injected the depletion of PD-1 is reduced, due to restricted perfusion, by a factor $\frac{1}{1+B / K_{P B}}$; since all other species of the model evolve within the tumor, we ignored the effect of restricted perfusion in setting up their dynamics. We conclude that $P_{1}$ satisfies the following equation:

$$
\begin{aligned}
\frac{\partial P_{1}}{\partial t}+ & \nabla \cdot\left(\mathbf{u} P_{1}\right)-\delta_{T} \nabla^{2} P_{1} \\
& =\rho_{P}\left[\text { RHS of Eq. (3) }+\varepsilon_{T} \times \text { RHS of Eq. (5) }\right] \\
& -\underbrace{\mu_{P A} P_{1} A}_{\text {depletion by anti-PD-1 }} \times \underbrace{\frac{1}{1+B / K_{P B}}}_{\text {blockade of perfusion by anti-VEGF }} .
\end{aligned}
$$

Similarly,

$$
\begin{aligned}
\frac{\partial P_{8}}{\partial t}+ & \nabla \cdot\left(\mathbf{u} P_{8}\right)-\delta_{T} \nabla^{2} P_{8} \\
& =\rho_{P}\left[\left(1+\varepsilon_{G} G\right) \times\right. \text { RHS of Eq. (4) } \\
& +\varepsilon_{G} T_{8} \times \text { RHS of Eq. (12) } \\
& \left.+\varepsilon_{G} T_{8} \nabla \cdot \mathbf{u} G+\varepsilon_{G}\left(\delta_{G}-\delta_{T}\right) T_{8} \nabla^{2} G-2 \varepsilon_{G} \delta_{T} \nabla T_{8} \cdot \nabla G\right] \\
& -\underbrace{\mu_{P A} P_{8} A}_{\text {depletion by anti-PD-1 }} \times \underbrace{\frac{1}{1+B / K_{P B}}}_{\text {blockade of perfusion by anti-VEGF }} .
\end{aligned}
$$

PD-L1 combines with PD-1 on the plasma membrane of $\mathrm{T}$ cells, to form a complex PD-1-PD-L1 (Q) [38, 39]. Denoting the association and disassociation rates of $Q$ by $\alpha_{P L}$ and $d_{Q}$, respectively, we can write

$$
P+L \underset{d_{Q}}{\stackrel{\alpha_{P L}}{\rightleftharpoons}} Q
$$

where $P=P_{1}+P_{8}$. The half-life of $Q$ is less then $1 \mathrm{~s}$ $\left(1.16 \times 10^{-5}\right.$ day $)$ [47], so that $d_{Q}$ is very large. Hence we may approximate the dynamical equation for $Q$ by the steady state equation, $\alpha_{P L} P L=d_{Q} Q$, so that

$$
Q=\sigma P L
$$

where $\sigma=\alpha_{P L} / d_{Q}$.

\section{Equation for anti-PD-1 (A)}

We assume that the drug enters the tumor from the boundary and quickly diffuses, so that its concentration is a constant $\gamma_{A}$ throughout the tumor during the dosing period. We denote by $\mu_{A P}$ the depletion rate of $A$ caused by blocking PD-1. Hence,

$$
\frac{\partial A}{\partial t}-\delta_{A} \nabla^{2} A=\gamma_{A} I_{A}(t)-\underbrace{\mu_{A P} P A}_{\text {depletion through blocking PD-1 }}-\underbrace{d_{A} A,}_{\text {degradation }}
$$

where $I_{A}(t)=1$ during dosing, and $I_{A}(t)=0$ otherwise.

\section{Equation for anti-VEGF (B)}

We denote by $\gamma_{B}$ the concentration of the injected $\operatorname{drug} B$ during the dosing period, and by $\mu_{B G}$ the depletion rate of $B$ blocking VEGF. The equation for $B$ is then given by

$$
\frac{\partial B}{\partial t}-\delta_{B} \nabla^{2} B=\gamma_{B} I(t)-\underbrace{\mu_{B G} G B}_{\text {depletion by VEGF }}-\underbrace{d_{B} B,}_{\text {degradation }}
$$

where $I_{B}(t)=1$ during dosing, and $I_{B}(t)=0$ otherwise.

\section{Equation for cells velocity (u)}

We assume that the density of each cell type in the growing tumor tends to a steady state, and take the density of the extracellular matrix (ECM) in steady state to be $0.6 \mathrm{~g} / \mathrm{cm}^{3}$.

We take the steady state density of endothelial cells to be $E=2.5 \times 10^{-3} \mathrm{~g} / \mathrm{cm}^{3}$ [43]. The steady state densities of the immune cells $D, T_{1}, T_{8}, T_{r}$ and $C$ (in units of $\mathrm{g} / \mathrm{cm}^{3}$ ) are taken to be (see Appendix: Parameter estimation)

$D=4 \times 10^{-4}, \quad T_{1}=2 \times 10^{-3}, \quad T_{8}=1 \times 10^{-3}, \quad T_{r}=5 \times 10^{-4}, \quad C=0.4$.

With these choices, the constant in Eq. (1) equal to 0.4064 . We further assume that all cells have approximately the same diffusion coefficient. Adding Eqs. (2)-(7), we get

$$
0.4064 \times \nabla \cdot \mathbf{u}=\sum_{j=2}^{7}[\operatorname{RHS} \text { of Eq. }(\mathrm{j})]
$$

To simplify the computations, we assume that the tumor is spherical and denote its radius by $r=R(t)$. We also assume that all the densities and concentrations are radially symmetric, that is, they are functions of $(r, t)$, where $0 \leq r \leq R(t)$. In particular, $\mathbf{u}=u(r, t) \mathbf{e}_{r}$, where $\mathbf{e}_{r}$ is the unit radial vector.

\section{Equation for free boundary (R)}

We assume that the free boundary $r=R(t)$ moves with the velocity of the cells, so that

$$
\frac{d R(t)}{d t}=u(R(t), t)
$$

\section{Boundary conditions}

We assume that the naive $\mathrm{CD} 4^{+} \mathrm{T}$ cells and $\mathrm{CD} 8^{+} \mathrm{T}$ cells which migrated from the lymph nodes into the tumor microenvironment have constant densities $\hat{T}_{1}$ and $\hat{T}_{8}$ at the tumor's boundary, and, that upon crossing the tumor 
boundary, $T_{1}$ and $T_{8}$ are activated by IL-12 and $T_{r}$ is activated by $T_{\beta}$. We then have the following flux conditions at the tumor's boundary:

$\frac{\partial T_{1}}{\partial r}+\sigma_{T}\left(I_{12}\right)\left(T_{1}-\hat{T}_{1}\right)=0, \frac{\partial T_{8}}{\partial r}+\sigma_{T}\left(I_{12}\right)\left(T_{8}-\hat{T}_{8}\right)=0$,

$\frac{\partial T_{r}}{\partial r}+\sigma_{T_{r}}\left(T_{\beta}\right)\left(T_{r}-\hat{T}_{1}\right)=0 \quad$ at $r=R(t)$,

where we take $\sigma_{T}\left(I_{12}\right)=\sigma_{0} \frac{I_{12}}{K_{I_{12}}+I_{12}}$ and $\sigma_{T_{r}}\left(T_{\beta}\right)=$ $\sigma_{0} \frac{T_{\beta}}{K_{T_{\beta}}+T_{\beta}}$. We assume that the endothelial cells that are attracted by the VEGF into the tumor microenvironment have constant density $\hat{E}$ at the tumor's boundary, and take

$$
\frac{\partial E}{\partial r}+\sigma_{E} \frac{G}{K_{G}+G}(E-\hat{E})=0 \quad \text { at } r=R(t) .
$$

The boundary condition for the oxygen is given by

$$
\frac{\partial W}{\partial r}+\sigma_{W}\left(W-W_{0}\right)=0 \quad \text { at } r=R(t),
$$

where $W_{0}$ is the normal level of oxygen concentration in the blood. We impose no-flux boundary condition for all the remaining variables:

No-flux for $D, C, I_{12}, I_{2}, T_{\beta}, G, P_{1}, P_{8}, A$, and $B$ at $r=R(t)$.

It is tacitly assumed here that the receptors PD-1 become active only after the $\mathrm{T}$ cells are already inside the tumor.

\section{Initial conditions}

We take the following initial values (in units of $\mathrm{g} / \mathrm{cm}^{3}$ ):

$D=2 \times 10^{-3}, T_{1}=4 \times 10^{-3}, T_{8}=2 \times 10^{-3}, T_{r}=3 \times 10^{-4}, E=2.45 \times 10^{-3}$,

$C=0.39565, I_{12}=2.88 \times 10^{-9}, I_{2}=4.74 \times 10^{-11}, T_{\beta}=2.57 \times 10^{-13}$,

$W=1.52 \times 10^{-4}, G=6.3 \times 10^{-8}, P_{1}=1.06 \times 10^{-9}, P_{8}=5.43 \times 10^{-11}$,

$R(0)=0.01 \mathrm{~cm}$.

Note that the total density of cells at time $t=0$ satisfies Eq. (1) with the already chosen constant 0.4064 . We also mention that the choice of initial conditions does not affect the simulation results after a few days.

\section{Results}

The simulations of the model were performed by Matlab, based on the moving mesh method for solving partial differential equations with free boundary [48] (see the section on computational method).

\section{Simulation results for mouse model}

Figure 3 shows the profiles of the average densities/concentrations of all the variables of the model in the control case (no drugs) and the tumor volume in the first 30 days. We note that each species $X$ reaches a nearly steady state that is approximately the halfsaturation value, $K_{X}$, as assumed in the estimation of some of the model parameters (in Appendix). This shows the consistency in the parameters estimation.
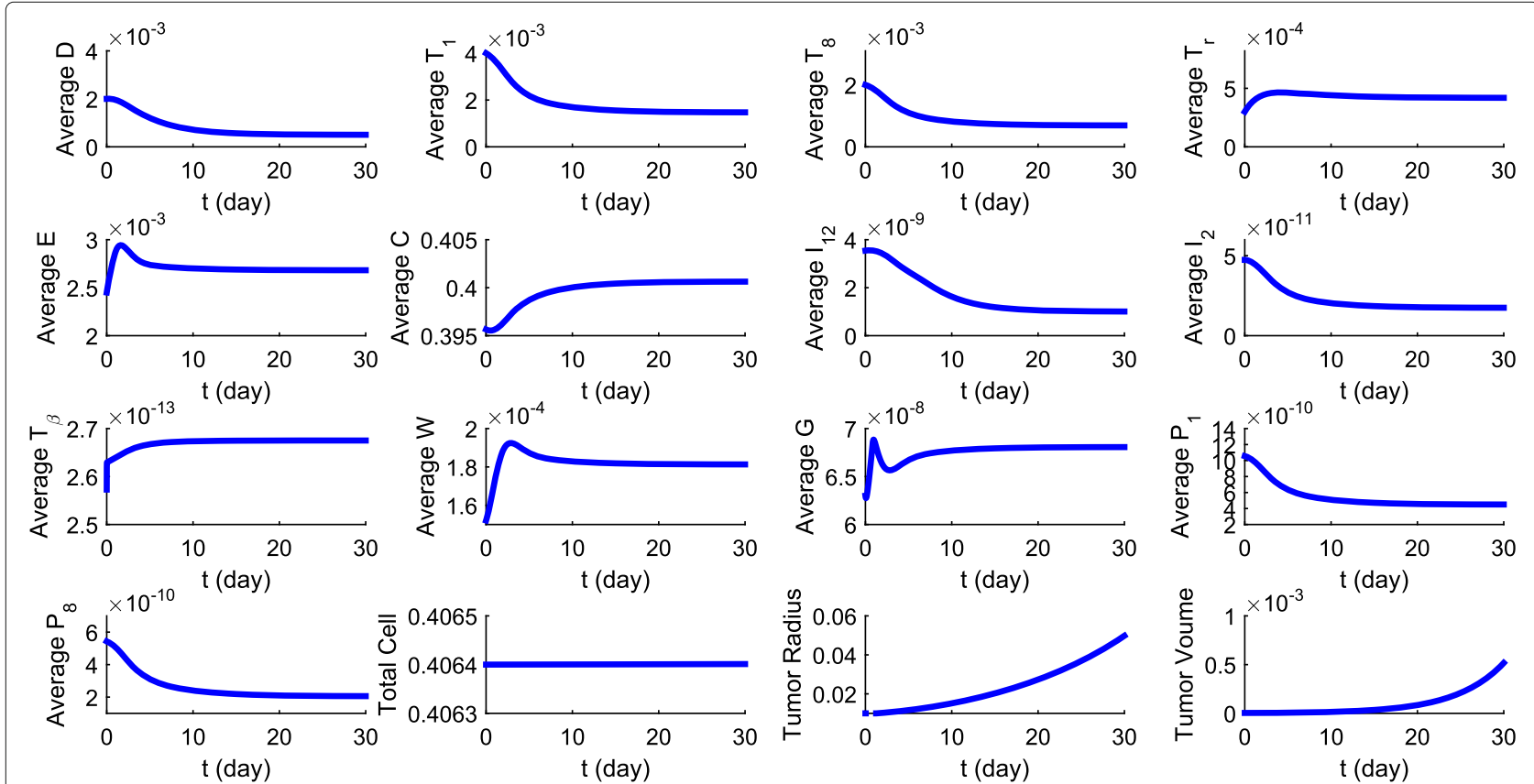

Fig. 3 Average densities/concentrations, in $\mathrm{g} / \mathrm{cm}^{3}$, of all the variables in the model with control case (no drugs). All parameter values are the same as in Tables 3 and 4, for a mouse model 
From Fig. 3 we see that in the first few days $E$, and corresponding $W$, are increasing before they begin to gradually decrease and reach a steady state. The production rate of $G$ is given by $\lambda(W) C$ where $\lambda(W)$ is bimodal and the oscillation in the profile of $G$ is affected by the bimodal profile of $W$ and the initial growth in the profile of $C$. The initial increase in $G$ results in initial decrease in $D$, and hence also a decrease in IL-12 and the T cells. The profile of $C$ is affected by the growth in $W$ and by the decrease in $T_{1}$ and $T_{8}: C$ begins to grow after a short time, but the growth rate decreases to near 0 as time increases.

Before applying our model to clinical situations, we need to determine the order of magnitude of $\gamma_{B}$ and $\gamma_{A}$. The parameter $\gamma_{B}$ is proportional to the amount of anti-VEGF administered to a patient, but it is difficult to determine this proportionality coefficient; the same is true for $\gamma_{A}$. We therefore conducted simulations with different choices of $\gamma_{B}, \gamma_{A}$ in order to find values for which the simulations agree qualitatively with mice experiments. One set of simulations is displayed in Fig. 4. Figure 4a shows that with $\gamma_{B}=3 \times 10^{-8} \mathrm{~g} / \mathrm{cm}^{3}$. day and $\gamma_{A}=3 \times 10^{-8} \mathrm{~g} / \mathrm{cm}^{3}$. day the anti-PD-1 as a single agent reduces the volume of tumor more than anti-VEGF as a single agent, in agreement with Fig. 1 in [29]. Figure $4 \mathrm{~b}$ shows that with $\gamma_{B}=$ $3.5 \times 10^{-8} \mathrm{~g} / \mathrm{cm}^{3}$. day and $\gamma_{A}=0.5 \times 10^{-8} \mathrm{~g} / \mathrm{cm}^{3}$. day the anti-VEGF as a single agent reduces the tumor volume more than the anti-PD-1 as single agent, in agreement with Fig. 4j in [27]. In Fig. 5 we see that (with $\gamma_{A}=0$ ) antiVEGF with $\gamma_{B}=2 \times 10^{-8} \mathrm{~g} / \mathrm{cm}^{3}$. day reduces significantly the PD-1 expression on $\mathrm{CD} 8^{+} \mathrm{T}$ cells, in agreement with experimental results in [27].

\section{Clinical trials in silico}

In clinical trials the treatment and follow-up periods are much longer than in mouse models, and the tumor growth is significantly slower. Accordingly, we shall modify some of the parameters in order to slow the growth of the tumor; these parameters are $\lambda_{D C}, \lambda_{E}, \lambda_{C W}$. We shall also decrease the range of the drug, from order of magnitude $10^{-8}$ to $10^{-9}-10^{-10}$.

We consider clinical treatment in cycles of 9 weeks, whereby each drug is given continuously for 3 weeks during a cycle with drug holiday for 6 weeks. We introduce three different schedules. In schedule S1 anti-PD-1 and anti-VEGF are both administered continuously in the first 3 weeks of the 9-week cycle. In schedule S2 anti-PD-1 is given continuously in the first 3 weeks, followed by antiVEGF in the next 3 weeks, with no drugs for the remaining 3 weeks of the cycle. Schedule S3 is similar to schedule S2 with anti-VEGF in the first 3 weeks and anti-PD-1 in the next 3 weeks. We refer to schedules S2 and S3 as non-overlapping schedules.

Figure 6 shows the profile of the tumor volume under schedules S1, S2 and S3 for four different dose pairs $\left(\gamma_{B}, \gamma_{A}\right)$. Table 2 summarizes the time, in weeks, at which the tumor volume decreased by $95 \%$ from its initial size. We see that the non-overlapping schedules S2 and S3 reduce the tumor volume significantly faster than schedule S1, and schedule S2 is somewhat more effective than schedule S3.

Figure 7 displays the density profiles of the immune cells, endothelial cells and cancer cells at different times along the radius of the tumor, with $\gamma_{A}=1.2 \times 10^{-10}$
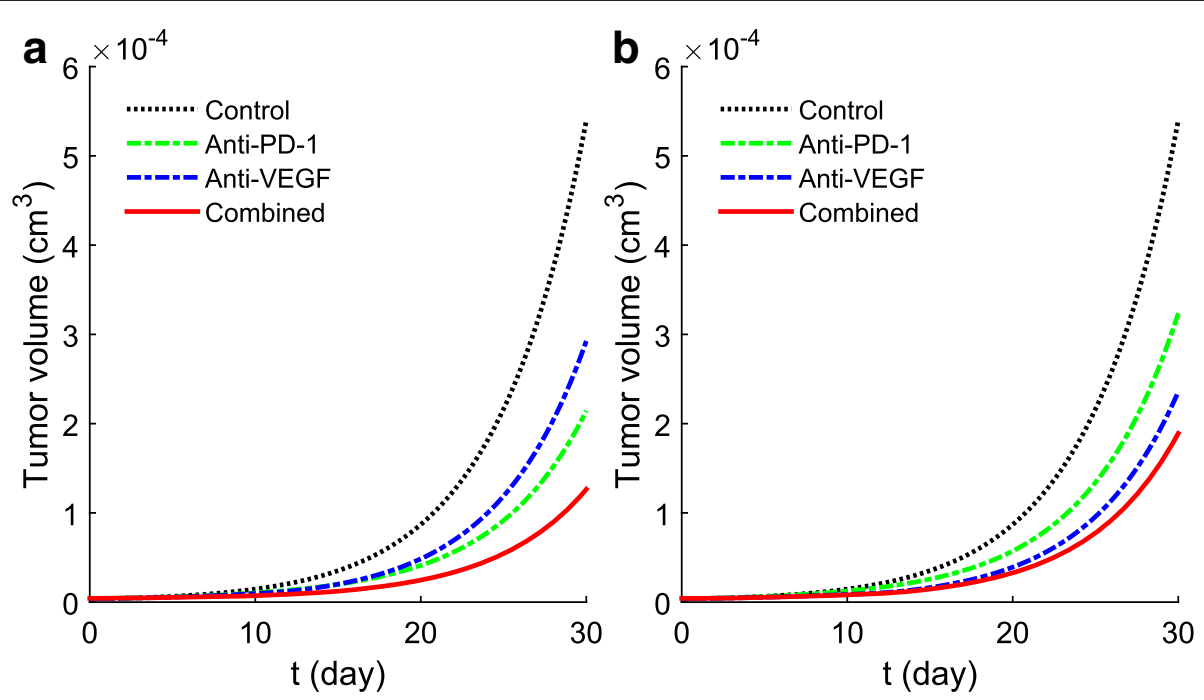

Fig. 4 Growth of tumor volume under treatment with $\gamma_{B}$ or $\gamma_{A}$, or combination $\left(\gamma_{B}, \gamma_{A}\right)$. The anti-VEGF or/and the anti-PD-1 treatment started at day 0 and continued for 10 days. $\mathbf{a} \gamma_{B}=3 \times 10^{-8} \mathrm{~g} / \mathrm{cm}^{3}$. day, $\gamma_{A}=3 \times 10^{-8} \mathrm{~g} / \mathrm{cm}^{3} \cdot$ day; $\mathbf{b} \gamma_{B}=3.5 \times 10^{-8} \mathrm{~g} / \mathrm{cm}^{3} \cdot$ day, $\gamma_{A}=0.5 \times 10^{-8}$ $\mathrm{g} / \mathrm{cm}^{3} \cdot$ day. All other parameters are same as in Fig. 3 

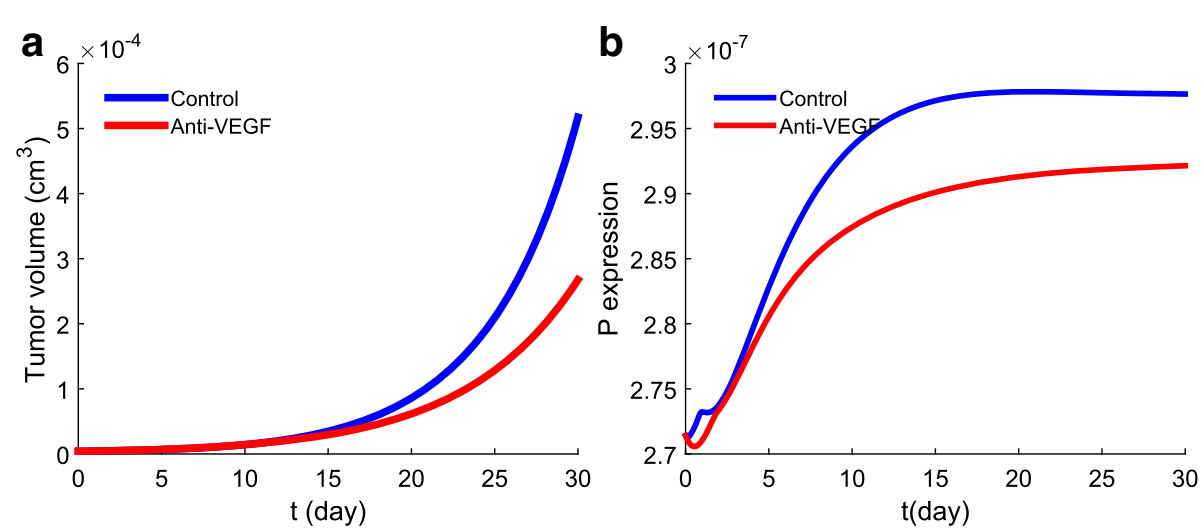

Fig. 5 Anti-VEGF decreases PD-1 expression on CD8 ${ }^{+} T$ cells. The treatment with anti-PD-1 drug started at day 0 and continued for 30 days with $\gamma_{B}=2 \times 10^{-8} \mathrm{~g} / \mathrm{cm}^{3}$. day (a) Growth of tumor volume. (b) Expression level of PD-1 on CD8 ${ }^{+} \mathrm{T}$ cells

$\mathrm{g} / \mathrm{cm}^{3} \cdot$ day, $\gamma_{B}=9.5 \times 10^{-9} \mathrm{~g} / \mathrm{cm}^{3} \cdot$ day. Figure 7 a shows the profiles under schedule $\mathrm{S} 2$ at times $t=0,8,15$ and 16 weeks, and Fig. $7 \mathrm{~b}$ shows the profiles under schedule $\mathrm{S} 3$ at times $t=0,8,18$ and 19 weeks. We see that the initially assumed flat density profiles are evolving to develop a distinct monotonic form. The density of cancer cells $(C)$ is increasing from the tumor core to the tumor boundary where the level of oxygen $(W)$ is more favorable to their abnormal proliferation. Since the total density of all the cells is constant (by Eq. (1)), the immune cells and the endothelial cells are "pushed" back toward the core of the tumor, so that their profile is monotone decreasing from the tumor core toward the tumor boundary.
Figure 8 shows "efficacy maps," namely, the time at which tumor volume was reduced by $95 \%$, under schedules S1, S2 and S3, for a range of the parameters $\gamma_{B}$ and $\gamma_{A}$. The horizontal axis scales the dose amount of anti-VEGF, $\gamma_{B}$, in units of $\mathrm{g} / \mathrm{cm}^{3} \cdot$ day, and the vertical axis scales the dose amount of anti-PD-1, $\gamma_{A}$, in unit of $\mathrm{g} / \mathrm{cm}^{3}$. day. The color columns show the time at which the tumor volume decreased by $95 \%$ from its initial size. We see that as $\gamma_{A}$ or $\gamma_{B}$ increases, the time when the tumor volume was reduced by $95 \%$ is decreased. Also, as in the special case of Fig. 6, schedules S2 and S3 reduce significantly the time for the $95 \%$ reduction, and the tumor volume reduction by schedule S2 is a little faster than by schedule S3.

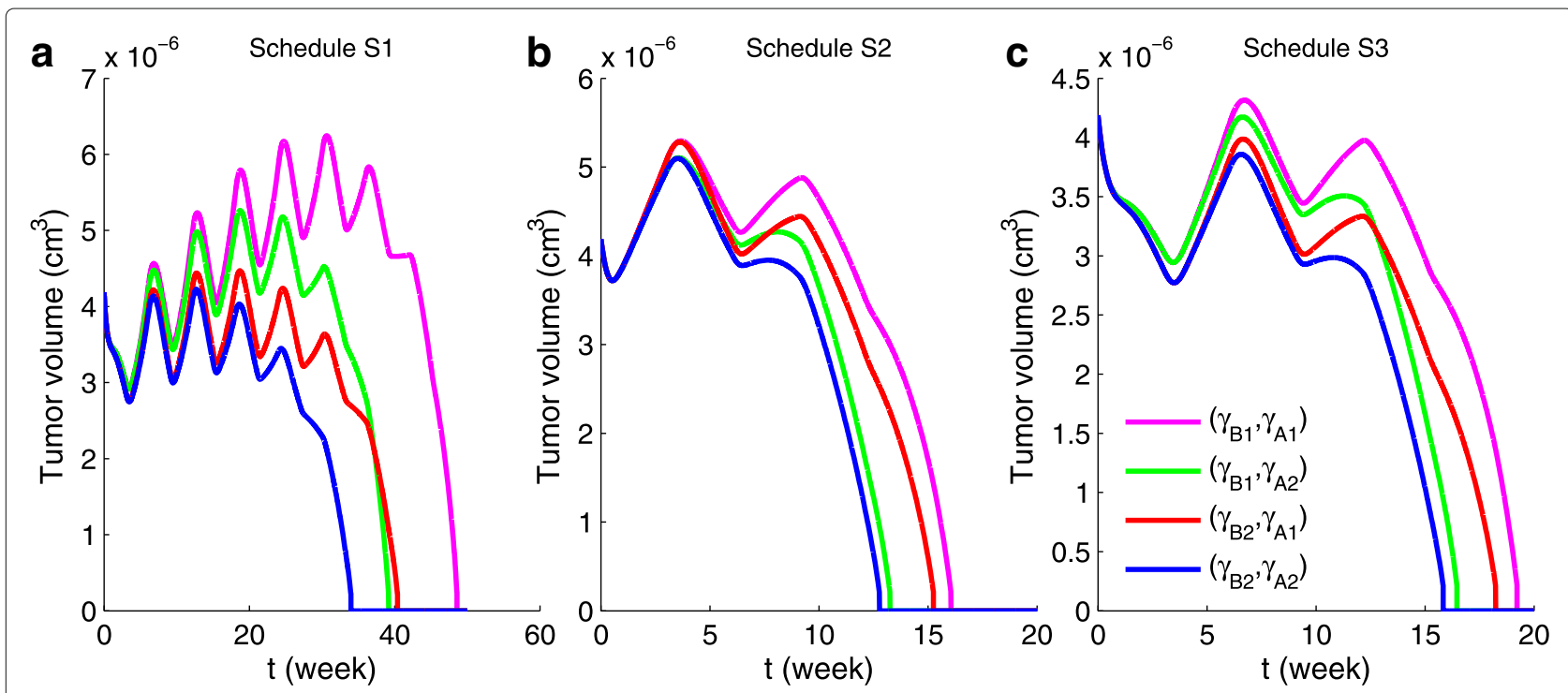

Fig. 6 Tumor volume under schedules S1, S2 and S3 for 4 pairs $\left(\gamma_{B}, \gamma_{A}\right)$. Here $\gamma_{B 1}=9.5 \times 10^{-9} \mathrm{~g} / \mathrm{cm}^{3} \cdot$ day, $\gamma_{A 1}=1.2 \times 10^{-10} \mathrm{~g} / \mathrm{cm}^{3} \cdot$ day, $\gamma_{B 2}=10 \times 10^{-9} \mathrm{~g} / \mathrm{cm}^{3} \cdot$ day, $\gamma_{A 2}=1.5 \times 10^{-10} \mathrm{~g} / \mathrm{cm}^{3} \cdot$ day. a Tumor volume under schedule S1; $\mathbf{b}$ Tumor volume under schedule S2; $\mathbf{c}$ Tumor volume under schedule $\mathrm{S3}$ 
Table 2 The time, in weeks, at which the tumor volume decreased to $5 \%$ of its initial size

\begin{tabular}{lllll}
\hline Schedule & $\left(\gamma_{B 1}, \gamma_{A 1}\right)$ & $\left(\gamma_{B 1}, \gamma_{A 2}\right)$ & $\left(\gamma_{B 2}, \gamma_{A 1}\right)$ & $\left(\gamma_{B 2}, \gamma_{A 2}\right)$ \\
\hline S1 & 48.59 & 39.17 & 40.4 & 33.99 \\
S2 & 16.05 & 13.26 & 15.25 & 12.78 \\
S3 & 19.22 & 16.46 & 18.24 & 15.83 \\
\hline
\end{tabular}

We conclude that non-overlapping treatment is far more beneficial than simultaneous treatment, and there is some advantage in injecting anti-PD-1 before anti-VEGF.

So far we considered the case where anti-VEGF blocks perfusion. We next consider briefly the case where antiVEGF increases perfusion (as in colon cancer [7, 8]). In this case we have to modify Eqs. (13) and (14) by replacing the term $1 /\left(1+B / K_{P B}\right)$ by $\left(1+\frac{B}{K_{B}+B}\right)$. In contrast to Figs. 6, 9 shows that simultaneous injection reduces the tumor volume (by 95\%) faster than non-overlapping injections: $\mathrm{S} 1$ is preferable to $\mathrm{S} 2$ and $\mathrm{S} 3$, while $\mathrm{S} 2$ is preferable to S3. These conclusions hold also when $\gamma_{B}$ and $\gamma_{A}$ vary in the same range as in Fig. 8.

\section{Sensitivity analysis}

We performed sensitivity analysis with respect to the tumor volume at day 30 for parameters $\lambda_{D C}, \lambda_{T_{8} I_{12}}, \lambda_{T_{r} G}$, $\lambda_{E}, \lambda_{G W}, \eta_{8}, K_{D G}, K_{T Q}, K_{T G}, K_{P B}$. Following the method of [49], we performed Latin hypercube sampling and generated 5000 samples to calculate the partial rank correlation coefficients (PRCC) and the $p$-values with respect to the tumor volume at day 30 . In sampling all the parameters, we took the range of each parameter from $1 / 2$ to twice its value in Tables 3 or 4. The results are shown in Fig. 10.

We see that parameters that promote the killing of cancer cells, such as $\lambda_{D C}, \lambda_{T_{8} I_{12}}$ and $\eta_{8}$, are negatively correlated with the tumor volume, while parameters that promote the inhibition of immune cells, such as $K_{D G}, K_{T Q}$ and $K_{T G}$, and the proliferation of endothelial cells and Tregs, such as $\lambda_{E}, \lambda_{T_{r} G}$ and $\lambda_{G W}$, are positively correlated with the tumor volume. We also see that the inhibition of perfusion of the anti-PD-1 drug by anti-VEGF promotes cancer growth, namely, $K_{P B}$ is positively correlated to the tumor volume. Among the various parameters, $\eta_{8}$ (the killing rate of cancer cells by $\mathrm{CD}^{+} \mathrm{T}$ cells) has the largest impact in reducing tumor volume, and $K_{T Q}$ (the parameter which increases the inhibition of $\mathrm{CD}^{+} \mathrm{T}$ cells by PD-1-PD-L1) has the largest impact on increasing tumor volume.

\section{Discussion}

Combination therapy for cancer has already shown improved benefits over a single agent therapy [50]. But significant challenges remain, as seen, for example, from the fact that of the successful phase II clinical trials with combination chemotherapy, less then $4 \%$ demonstrated, in Phase III, improvement of care within 5 years [11]. It was suggested in [13] that a selection of clinical trials needs to include scientific rationale underlying the data and hypothesis for the combination. Combination clinical trials should be preceded by analysis of the expected
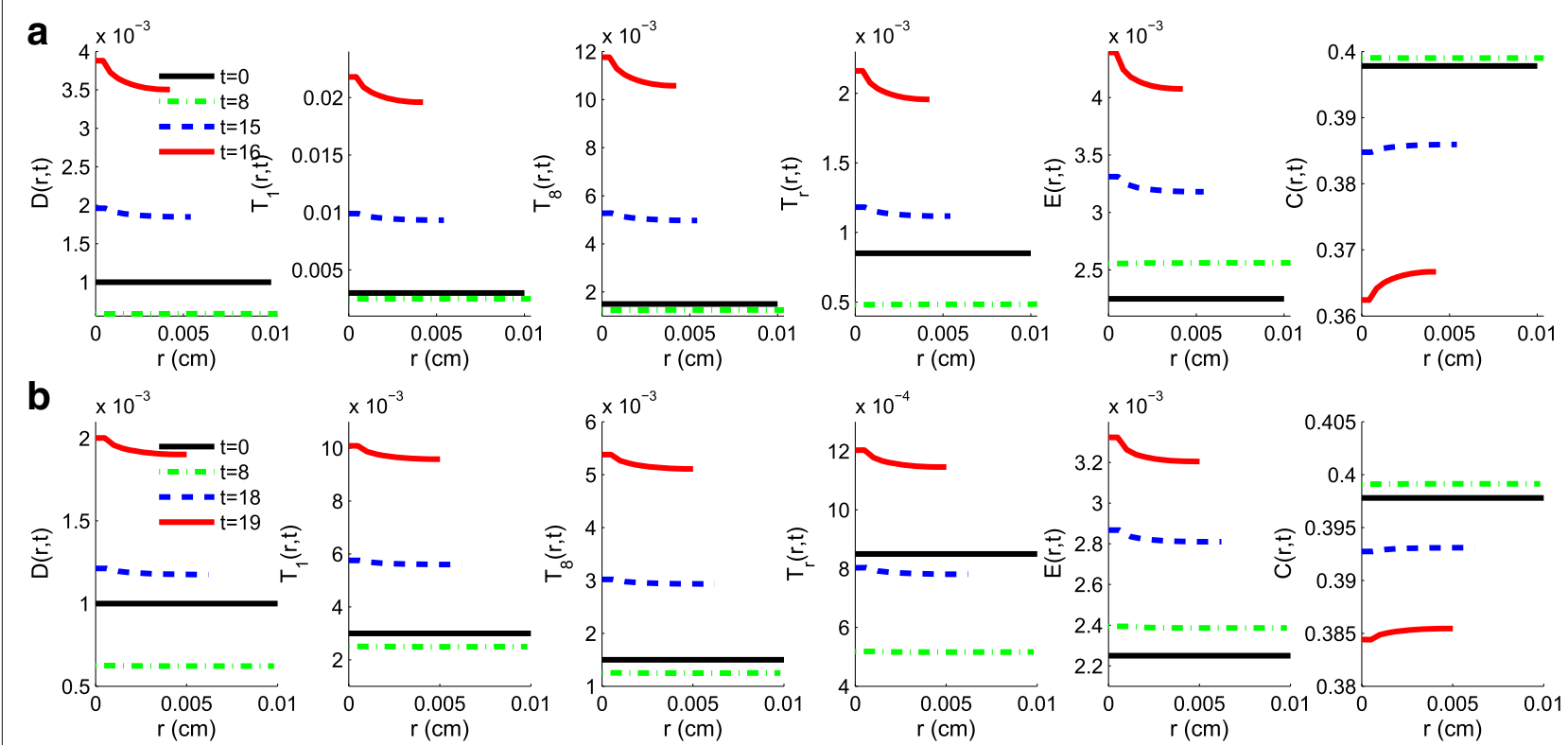

Fig. 7 Spatial profiles of the densities of dendritic cells, T cells, endothelial cells and cancer cells with $\gamma_{A}=1.2 \times 10^{-10} \mathrm{~g} / \mathrm{cm}^{3} \cdot$ day, $\gamma_{B}=9.5 \times 10^{-9}$ $\mathrm{g} / \mathrm{cm}^{3} \cdot$ day. a Profiles under schedule S2 at day $t=0,8,15$ and 16 weeks. b Profiles under schedule S3 at days $t=0,8,18$ and 19 weeks 

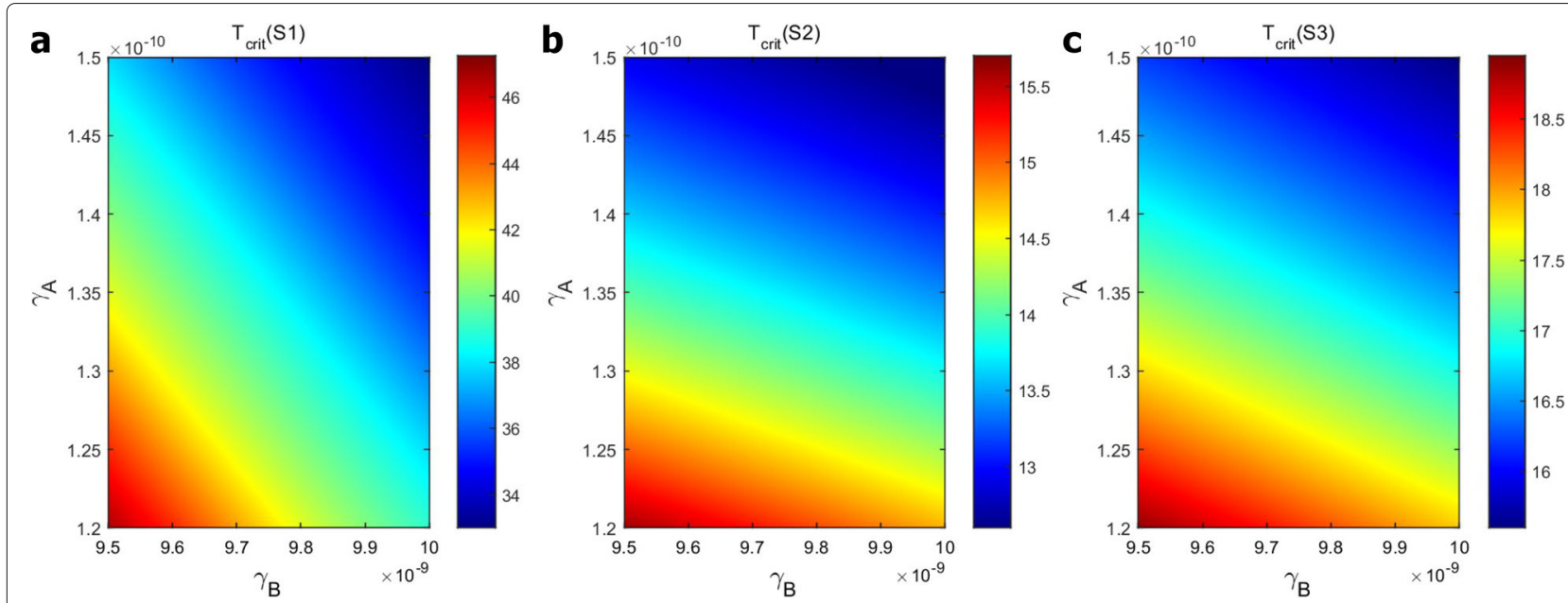

Fig. 8 Efficacy maps: The time in weeks $\left(T_{c r i t}\right)$ at which the tumor volume decreases by $95 \%$ from its initial size under treatment with $\left(\gamma_{B}, \gamma_{A}\right)$. a Efficacy map under schedule S1; b Efficacy map under schedule S2; $\mathbf{c}$ Efficacy map under schedule S3. The color columns show the time at which the tumor volume was reduced by $95 \%$

interactions between the diverse agents, addressing, for example the following questions:

1. Are the two drugs positively correlated at any amount of dose, and, if so, what should be the most beneficial ratio between the two agents?

2. If the drugs are not always positively correlated, what are the zones of antagonism, i.e., what are the amounts of, and the ratios between, the agents in the combination that may decrease the treatment benefits, and should not be used in clinical trials?
3. If the two drugs are injected intermittently, should they be injected simultaneously or non-overlappingly, and, in the latter case, which drug should be injected first?

In [14] and [15] we addressed the questions (i) and (ii) in the case where one of the drugs is a checkpoint inhibitor (anti-PD-1), and the second drug is a cancer vaccine [14] or a BRAF-inhibitor [15]. In the present paper we addressed the question (iii) when the two drugs are antiPD-1 and anti-VEGF. Anti-VEGF is known to block the
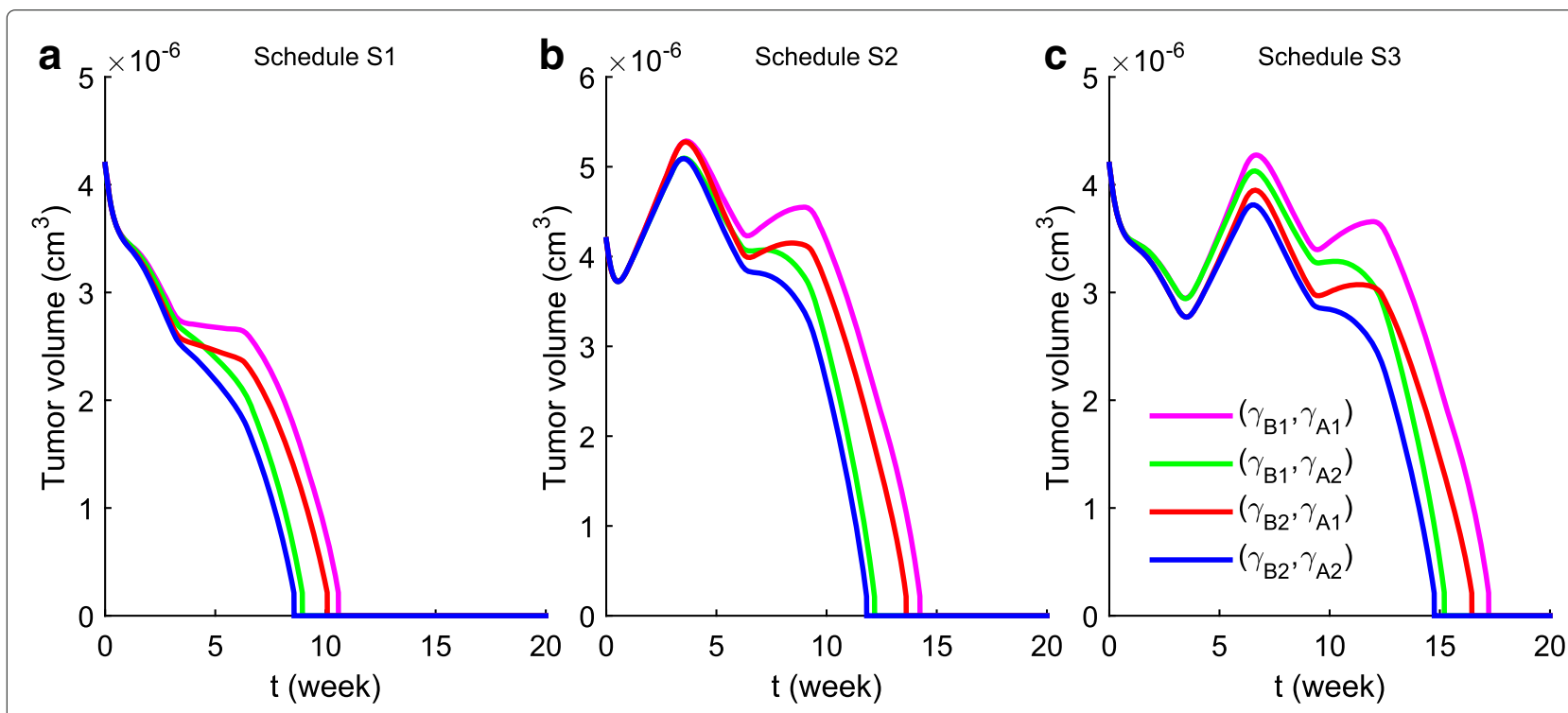

Fig. 9 Tumor volume under the schedules S1, S2 and S3 for 4 pairs $\left(\gamma_{B}, \gamma_{A}\right)$. Here $\gamma_{B 1}=9.5 \times 10^{-9} \mathrm{~g} / \mathrm{cm}^{3} \cdot$ day, $\gamma_{A 1}=1.2 \times 10^{-10} \mathrm{~g} / \mathrm{cm}^{3} \cdot$ day, $\gamma_{B 2}=9.5 \times 10^{-9} \mathrm{~g} / \mathrm{cm}^{3} \cdot$ day, $\gamma_{A 2}=1.5 \times 10^{-10} \mathrm{~g} / \mathrm{cm}^{3} \cdot$ day. a Tumor volume under schedule S1; b Tumor volume under schedule S2; $\mathbf{c}$ Tumor volume under schedule $\mathrm{S} 3$ 
Table 3 Summary of parameter values

\begin{tabular}{|c|c|c|c|}
\hline Notation & Description & Value used & References \\
\hline$\overline{\delta_{D}}$ & Diffusion coefficient of DCs & $8.64 \times 10^{-7} \mathrm{~cm}^{2}$ day $^{-1}$ & [59] \\
\hline$\delta_{T}$ & Diffusion coefficient of T cells & $8.64 \times 10^{-7} \mathrm{~cm}^{2}$ day $^{-1}$ & [59] \\
\hline$\delta_{E}$ & Diffusion coefficient of endothelial cells & $8.64 \times 10^{-7} \mathrm{~cm}^{2}$ day $^{-1}$ & [59] \\
\hline$\delta_{C}$ & Diffusion coefficient of tumor cells & $8.64 \times 10^{-7} \mathrm{~cm}^{2}$ day $^{-1}$ & [59] \\
\hline$\delta_{1 / 2}$ & Diffusion coefficient of IL-12 & $6.05 \times 10^{-2} \mathrm{~cm}^{2} \mathrm{day}^{-1}$ & {$[15]$} \\
\hline$\delta_{12}$ & Diffusion coefficient of IL-2 & $9.58 \times 10^{-2} \mathrm{~cm}^{2} \mathrm{day}^{-1}$ & {$[15]$} \\
\hline$\delta_{T_{\beta}}$ & Diffusion coefficient of TGF- $\beta$ & $8.52 \times 10^{-2} \mathrm{~cm}^{2} \mathrm{day}^{-1}$ & {$[15]$} \\
\hline$\delta_{W}$ & Diffusion coefficient of oxygen & $0.8 \mathrm{~cm}^{2}$ day $^{-1}$ & Estimated \\
\hline$\delta_{G}$ & Diffusion coefficient of VEGF & $8.64 \times 10^{-2} \mathrm{~cm}^{2} \mathrm{day}^{-1}$ & {$[57]$} \\
\hline$\delta_{A}$ & Diffusion coefficient of anti-PD-L1 & $4.73 \times 10^{-2} \mathrm{~cm}^{2} \mathrm{day}^{-1}$ & {$[15]$} \\
\hline$\delta_{B}$ & Diffusion coefficient of anit-VGEF & $4.70 \times 10^{-2} \mathrm{~cm}^{2}$ day $^{-1}$ & Estimated \\
\hline$\sigma_{T}$ & Flux rate of $T_{1}$ and $T_{8}$ cells at the boundary & $1 \mathrm{~cm}^{-1}$ & [59] \\
\hline$\sigma_{E}$ & Flux rate of $T_{1}$ and $T_{8}$ cells at the boundary & $1 \mathrm{~cm}^{-1}$ & {$[59]$} \\
\hline$\chi_{G}$ & Chemoattraction coefficient of VEGF & $10 \mathrm{~cm}^{5} / \mathrm{g} \cdot$ day & {$[64,65]$} \\
\hline$\lambda_{D C}$ & Activation rate of DCs by tumor cells (mice) & 17.5 day & Estimated \\
\hline$\lambda_{D C}$ & Activation rate of DCs by tumor cells (humans) & 7.5 day & Estimated \\
\hline$\lambda_{T_{1} / 12}$ & Activation rate of $\mathrm{CD}^{+}{ }^{+} \mathrm{T}$ cells by $\mathrm{IL}-12$ & 11.65 day $^{-1}$ & Estimated \\
\hline$\lambda_{T_{1} / 2}$ & Activation rate of $\mathrm{CD}^{+}{ }^{+} \mathrm{T}$ cells by $\mathrm{IL}-2$ & 0.25 day $^{-1}$ & [59] \\
\hline$\lambda_{T_{8} / 12}$ & Activation rate of $\mathrm{CD}^{+}{ }^{+} \mathrm{T}$ cells by $\mathrm{IL}-12$ & 10.38 day $^{-1}$ & Estimated \\
\hline$\lambda_{T_{8} / 2}$ & Activation rate of $\mathrm{CD} 8+\mathrm{T}$ cells by IL-2 & 0.25 day $^{-1}$ & [59] \\
\hline$\lambda_{T_{r} T_{\beta}}$ & Activation rate of Tregs by TGF- $\beta$ & 0.415 day $^{-1}$ & Estimated \\
\hline$\lambda_{T_{r} G}$ & Activation rate of Tregs by VEGF & 0.083 day $^{-1}$ & Estimated \\
\hline$\lambda_{E}$ & Growth rate of endothelial cells (mice) & $2.77 \times 10^{7} \mathrm{~cm}^{3} / \mathrm{g} \cdot$ day & Estimated \\
\hline$\lambda_{E}$ & Growth rate of endothelial cells (humans) & $2.08 \times 10^{7} \mathrm{~cm}^{3} / \mathrm{g} \cdot$ day & Estimated \\
\hline$\lambda \subset w$ & Growth rate of cancer cells (mice) & 2.24 day $^{-1}$ & Estimated \\
\hline$\lambda_{C W}$ & Growth rate of cancer cells (humans) & 1.76 day $^{-1}$ & Estimated \\
\hline$\lambda /_{122} D$ & Production rate of IL-12 by DCs & $2.21 \times 10^{-6}$ day $^{-1}$ & {$[15]$} \\
\hline$\lambda / / 2 T_{1}$ & Production rate of $\mathrm{IL}-2$ by $\mathrm{CD} 4^{+} \mathrm{T}$ cells & $2.82 \times 10^{-8}$ day $^{-1}$ & {$[15]$} \\
\hline$\lambda_{T_{\beta} C}$ & Production rate of TGF- $\beta$ by cancer cells & $3.27 \times 10^{-10}$ day $^{-1}$ & Estimated \\
\hline$\lambda_{T_{\beta} T_{r}}$ & Production rate of TGF- $\beta$ by Tregs & $5.57 \times 10^{-9}$ day $^{-1}$ & {$[61]$} \\
\hline$\lambda_{W E}$ & Production rate of oxygen by endothelial cells & $7 \times 10^{-2} /$ day & {$[43]$} \\
\hline$\lambda_{G W}$ & Production rate of VEGF by cancer cells & $2.21 \times 10^{-6}$ day $^{-1}$ & Estimated \\
\hline$\varepsilon_{T}$ & Relative expression of PD-1 in Tregs & 0.8 & {$[15]$} \\
\hline$\varepsilon_{C}$ & Relative expression of PD-L1 in tumor cells & 0.01 & {$[15]$} \\
\hline$\varepsilon_{G}$ & Relative rate of PD-1 promotion by VEGF & $1.43 \times 10^{6} \mathrm{~cm}^{3} / \mathrm{g}$ & Estimated \\
\hline
\end{tabular}

perfusion of chemotherapy in melanoma [3], breast cancer $[4,5,9]$ and ovarian cancer [6], but to increase perfusion in colon cancer [7].

We developed a mathematical model and simulations for in silico clinical trials that addressed the complexity of interactions among the two drugs. The model is represented by a system of PDEs that includes the most relevant cells and cytokines associated with the treatment. The simulations show that in the case where anti-VEGF decreases the perfusion of the anti-PD-1, the time it takes to reduce tumor volume by $95 \%$ is much shorter when the injections of the two drugs are non-overlapping than when the injections are given at the same time. Furthermore, in the non-overlapping treatment, if we inject the anti-PD-1 first we get the $95 \%$-reduction somewhat faster than if we inject anti-VEGF first.

On the other hand, in the case when anti-VEGF increases the perfusion of anti-PD-1, a treatment with 
Table 4 Summary of parameter values

\begin{tabular}{|c|c|c|c|}
\hline Notation & Description & Value used & References \\
\hline$\overline{d_{D}}$ & Death rate of DCs & 0.1 day $^{-1}$ & {$[59]$} \\
\hline$d_{T_{1}}$ & Death rate of $\mathrm{CD} 4^{+} \mathrm{T}$ cells & 0.197 day $^{-1}$ & [59] \\
\hline$d_{T_{8}}$ & Death rate of $\mathrm{CD}^{+}{ }^{+} \mathrm{T}$ cells & 0.18 day $^{-1}$ & {$[59]$} \\
\hline$d_{T_{r}}$ & Death rate of Tregs & 0.2 day $^{-1}$ & {$[61]$} \\
\hline$d_{E}$ & Death rate of endothelial cells & 0.69 day $^{-1}$ & {$[43]$} \\
\hline$d_{C}$ & Death rate of tumor cells & 0.17 day $^{-1}$ & {$[59]$} \\
\hline$d_{12}$ & Degradation rate of IL-12 & 1.38 day $^{-1}$ & [59] \\
\hline$d_{12}$ & Degradation rate of IL-2 & 2.376 day $^{-1}$ & [59] \\
\hline$d_{T_{\beta}}$ & Degradation rate of TGF- $\beta$ & 499.066 day $^{-1}$ & [15] \\
\hline$d_{W}$ & Take-up rate of oxygen by cells & 1.04 day $^{-1}$ & Estimated \\
\hline$d_{G}$ & Degradation rate of VEGF & 12.6 day $^{-1}$ & [43] \\
\hline$d_{A}$ & Degradation rate of anti-PD-L1 & 0.34 day $^{-1}$ & Estimated \\
\hline$\eta_{1}$ & Killing rate of cancer cells by $T_{1}$ & $30.19 \mathrm{~cm}^{3} / \mathrm{g} \cdot$ day & Estimated \\
\hline$\eta_{8}$ & Killing rate of cancer cells by $T_{8}$ & $60.375 \mathrm{~cm}^{3} / \mathrm{g} \cdot$ day & Estimated \\
\hline$d_{B}$ & Degradation rate of anti-VEGF & 0.17 day $^{-1}$ & Estimated \\
\hline$\mu_{P A}$ & Blocking rate of PD-1 by anti-PD-1 & $4.33 \times 10^{7} \mathrm{~cm}^{3} / \mathrm{g} \cdot$ day & Estimated \\
\hline$\mu_{A P}$ & Degradation rate of anti-PD-1 in blocking PD-1 & $4.33 \times 10^{7} \mathrm{~cm}^{3} / \mathrm{g} \cdot$ day & Estimated \\
\hline$\mu_{G B}$ & Blocking rate of VEGF by anti-VEGF & $2.19 \times 10^{7} \mathrm{~cm}^{3} / \mathrm{g} \cdot$ day & Estimated \\
\hline$\mu_{B G}$ & Degradation rate of anti-VEGF in blocking VEGF & $1.31 \times 10^{8} \mathrm{~cm}^{3} / \mathrm{g} \cdot$ day & Estimated \\
\hline$K_{D}$ & Half-saturation of $\mathrm{CD}^{+}{ }^{+} \mathrm{T}$ cells & $4 \times 10^{-4} \mathrm{~g} / \mathrm{cm}^{3}$ & [15] \\
\hline$K_{T_{1}}$ & Half-saturation of $\mathrm{CD}^{+}{ }^{+} \mathrm{T}$ cells & $2 \times 10^{-3} \mathrm{~g} / \mathrm{cm}^{3}$ & [15] \\
\hline$K_{T_{8}}$ & Half-saturation of $\mathrm{CD}^{+} \mathrm{T}$ cells & $1 \times 10^{-3} \mathrm{~g} / \mathrm{cm}^{3}$ & {$[15]$} \\
\hline$K_{T_{r}}$ & Half-saturation of Tregs & $5 \times 10^{-4} \mathrm{~g} / \mathrm{cm}^{3}$ & {$[15]$} \\
\hline$K_{E}$ & Half-saturation of endothelial cells & $2.5 \times 10^{-3} \mathrm{~g} / \mathrm{cm}^{3}$ & [43] \\
\hline$K_{C}$ & Half-saturation of tumor cells & $0.4 \mathrm{~g} / \mathrm{cm}^{3}$ & {$[15]$} \\
\hline$K_{12}$ & Half-saturation of IL-12 & $8 \times 10^{-10} \mathrm{~g} / \mathrm{cm}^{3}$ & [15] \\
\hline$K_{1 / 2}$ & Half-saturation of IL-2 & $2.37 \times 10^{-11} \mathrm{~g} / \mathrm{cm}^{3}$ & [15] \\
\hline$K_{T_{\beta}}$ & Half-saturation of TGF- $\beta$ & $2.68 \times 10^{-13} \mathrm{~g} / \mathrm{cm}^{3}$ & [15] \\
\hline$K_{W}$ & Half-saturation of oxygen & $1.69 \times 10^{-4} \mathrm{~g} / \mathrm{cm}^{3}$ & [43] \\
\hline$K_{G}$ & Half-saturation of VGEF & $7 \times 10^{-8} \mathrm{~g} / \mathrm{cm}^{3}$ & [43] \\
\hline$K_{\pi \pi_{r}}$ & Inhibition of function of $\mathrm{T}$ cells by Tregs & $5 \times 10^{-4} \mathrm{~g} / \mathrm{cm}^{3}$ & [15] \\
\hline$K_{T Q}^{\prime}$ & Inhibition of function of T cells by PD-1-PD-L1 & $1.68 \times 10^{-18} \mathrm{~g}^{2} / \mathrm{cm}^{6}$ & Estimated \\
\hline$K_{P B}$ & Block of anti-PD-1 perfusion by anti-VEGF (mice) & $1 \times 10^{-8} \mathrm{~g} / \mathrm{cm}^{3}$ & Estimated \\
\hline$K_{P B}$ & Block of anti-PD-1 perfusion by anti-VEGF (humans) & $1 \times 10^{-9} \mathrm{~g} / \mathrm{cm}^{3}$ & Estimated \\
\hline$D_{0}$ & Density of immature DCs & $2 \times 10^{-5} \mathrm{~g} / \mathrm{cm}^{3}$ & [59] \\
\hline$T_{10}$ & Density of naive $\mathrm{CD}^{+}{ }^{+} \mathrm{T}$ cells & $4 \times 10^{-4} \mathrm{~g} / \mathrm{cm}^{3}$ & [15] \\
\hline$T_{80}$ & Density of naive $C D 8^{+} \mathrm{T}$ cells & $2 \times 10^{-4} \mathrm{~g} / \mathrm{cm}^{3}$ & [15] \\
\hline$E_{M}$ & Carrying capacity of endothelial cells & $5 \times 10^{-3} \mathrm{~g} / \mathrm{cm}^{3}$ & {$[43]$} \\
\hline$C_{M}$ & Carrying capacity of cancer cells & $0.8 \mathrm{~g} / \mathrm{cm}^{3}$ & [59] \\
\hline$G_{0}$ & Threshold VEGF concentration & $3.65 \times 10^{-10} \mathrm{~g} / \mathrm{cm}^{3}$ & {$[43]$} \\
\hline$\hat{T}_{1}$ & Density of $\mathrm{CD} 4^{+} \mathrm{T}$ cells from lymph node & $4 \times 10^{-3} \mathrm{~g} / \mathrm{cm}^{3}$ & [15] \\
\hline$\hat{T}_{8}$ & Density of $C D 8^{+} T$ cells from lymph node & $2 \times 10^{-3} \mathrm{~g} / \mathrm{cm}^{3}$ & [15] \\
\hline$\hat{E}$ & Density of endothelial cells from outside of tumor & $5 \times 10^{-3} \mathrm{~g} / \mathrm{cm}^{3}$ & Estimated \\
\hline$W^{*}$ & Hypoxia threshold oxygen level & $1.69 \times 10^{-4} \mathrm{~g} / \mathrm{cm}^{3}$ & [44] \\
\hline$W_{0}$ & Normal threshold oxygen level & $4.65 \times 10^{-4} \mathrm{~g} / \mathrm{cm}^{3}$ & {$[44]$} \\
\hline
\end{tabular}


simultaneous infections is more beneficial than a treatment with non-overlapping injections.

The optimal scheduling in combination therapy for cancer was considered in several publications, both in terms of toxicity [51] and efficacy [52-54]. The present paper considered the efficacy question by a mathematical model. The method and results of the paper can be extended to other combinations, for example to a chemotherapeutic agent combined with anti-VEGF, and they could play an important role in the design of clinical trials, where scheduling strategies may significantly affect the outcome.

\section{Conclusions}

The design of cancer clinical trials with combination of two drugs should take into account the potential interactions between the two agents, which may suggest an optimal scheduling strategy in the administration of the drugs. Mathematical models can play a useful role in this process. This was illustrated in the case where the drugs are anti-VEGF and anti-PD-1. Anti-VEGF increases the activation of anti-cancer cells, but it also modifies the perfusion of other drugs. Using a mathematical model we showed that a non-overlappling adminstration of the two drugs is more effective in reducing tumor volume than simultaneous administration of the drugs in the case where anti-VEGF degrades perfusion, as it occurs in some cancers, while the opposite is true when perfusion is enhanced by anti-VEGF. The mathematical methodology developed in this paper could be extended to treatment with other combinations of drugs.

\section{Appendix}

\section{Parameter estimation}

Half-saturation

In an expression of the form $Y \frac{X}{K_{X}+X}$ where $Y$ is activated by $X$, the parameter $K_{X}$ is called the half-saturation of $X$.

We assume that if the average density (or concentration) of $X$,

$$
\frac{\int X d x}{\int d X}
$$

converges to a steady state $X_{0}$, then

$$
\frac{X_{0}}{K_{X}+X_{0}}
$$

is not "too small" and not "too close" to 1 , and for definiteness we take

$$
\frac{X_{0}}{K_{X}+X_{0}}=\frac{1}{2}
$$

so that

$$
K_{X}=X_{0} .
$$

To estimate parameters, we assume that all the average densities and concentrations converge to their respective steady states, and thus use Eq. (28) in each of the steady state equations of the model.

\section{Diffusion coefficients}

We use the following relation for estimating the diffusion coefficient of a protein $p$ [55]:

$$
\delta_{p}=\frac{M_{G}^{1 / 3}}{M_{p}^{1 / 3}} \delta_{G},
$$

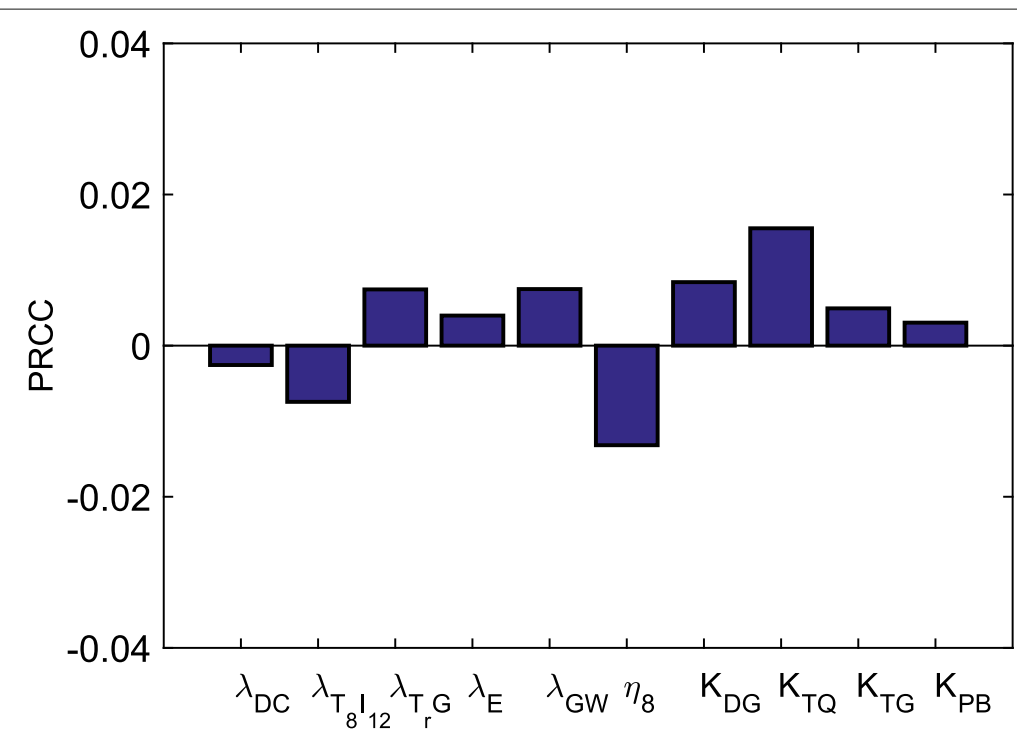

Fig. 10 Statistically significant PRCC values ( $p$-value $<0.01$ ) for tumor volume at day 30 
where $M_{G}$ and $\delta_{G}$ are respectively the molecular weight and diffusion coefficient of VEGF, $M_{p}$ is the molecular weight of $p$, and $M_{G}=24 \mathrm{kDa}$ [56] and $\delta_{G}=8.64 \times 10^{-2}$ $\mathrm{cm}^{2}$ day $^{-1}$ [57]. Since, $M_{B}=149 \mathrm{kDa}$ (bevacizumab), we get $\delta_{B}=4.70 \times 10^{-2} \mathrm{~cm}^{2}$ day $^{-1}$. The diffusion coefficient of oxygen in the extracellular matrix (ECM) in the range of $7 \times 10^{-6}-2 \times 10^{-5} \mathrm{~cm}^{2} / \mathrm{s}$ [58]; we take it to be $\delta_{W}=0.8 \mathrm{~cm}^{2} /$ day.

Eq. (2).

From the steady state of Eq. (2) (more precisely, by setting to zero the RHS of Eq. (2)), we get $\lambda_{D C} D_{0} \frac{C}{K_{C}+C} \cdot \frac{1}{1+G / K_{D G}}=$ $d_{D} D$, where by [15], $d_{D}=0.1 /$ day, $C=K_{C}=0.4 \mathrm{~g} / \mathrm{cm}^{3}$, $D=K_{D}=4 \times 10^{-4} \mathrm{~g} / \mathrm{cm}^{3}, D_{0}=2 \times 10^{-5} \mathrm{~g} / \mathrm{cm}^{3}$. We assume that $K_{D G}=4 K_{G}$ where $K_{G}=7 \times 10^{-8} \mathrm{~g} / \mathrm{cm}^{3}$ [43]; hence $\lambda_{D C}=2.5 d_{D} D / D_{0}=5 /$ day. For simplicity we had assumed that the source of inactive dendritic cells, $D_{0}$, is constant. However, this source actually decreases as more dendritic cells become activated. We take this into count by increasing $\lambda_{D C}$, taking $\lambda_{D C}=17.5 /$ day in mice and $\lambda_{D C}=7.5 /$ day in humans.

Eqs. (3) and (4).

We assume that in steady state, $Q / K_{T Q}=2$ (the value of $K_{T Q}$ is derived in the estimates for Eqs. (13)-(17)). We also assume that $K_{T G}=4 K_{G}$ where $K_{G}=7 \times 10^{-8} \mathrm{~g} / \mathrm{cm}^{3}$ [43]. From the steady state of Eq. (3), we get

$$
\left(\lambda_{T_{1} I_{12}} T_{10} \cdot \frac{1}{2} \cdot \frac{1}{2} \cdot \frac{4}{5}+\lambda_{T_{1} I_{2}} T_{1} \cdot \frac{1}{2}\right) \cdot \frac{1}{3}-d_{T_{1}} T_{1}=0,
$$

where, by [15], $\lambda_{T_{1} I_{2}}=0.25 /$ day, $d_{T_{1}}=0.197 /$ day, $T_{10}=$ $4 \times 10^{-4} \mathrm{~g} / \mathrm{cm}^{3}$ and $T_{1}=K_{T_{1}}=2 \times 10^{-3} \mathrm{~g} / \mathrm{cm}^{3}$. Hence $\lambda_{T_{1} I_{12}}=11.65 /$ day.

From the steady state of Eq. (4), we have

$$
\left(\lambda_{T_{8} I_{12}} T_{80} \cdot \frac{1}{2} \cdot \frac{1}{2} \cdot \frac{4}{5}+\lambda_{T_{1} I_{2}} T_{8} \cdot \frac{1}{2}\right) \cdot \frac{1}{3}-d_{T_{8}} T_{8}=0
$$

where by [15], $\lambda_{T_{8} I_{2}}=0.25 /$ day, $d_{T_{8}}=0.18 /$ day, $T_{80}=$ $2 \times 10^{-4} \mathrm{~g} / \mathrm{cm}^{3}, T_{8}=K_{T_{8}}=1 \times 10^{-3} \mathrm{~g} / \mathrm{cm}^{3}$. Hence $\lambda_{T_{8} I_{12}}=10.38 /$ day.

As in the case of Eq. (2), we had ignored the decrease in the sources $T_{10}$ and $T_{80}$ as more of these cells become activated, but we also ignored the contribution of the flux of $\mathrm{T}$ cells at the tumor's boundary. We assume that the flux of $\mathrm{T}$ cells compensates for decrease in the source of the inactive $T$ cells, and retain the above values of $\lambda_{T_{1} I_{12}}$ and $\lambda_{T_{8} I_{12}}$. The same considerations apply in the case of $T_{r}$.

\section{Eq. (5).}

We assume that TGF- $\beta$ activates Tregs more than VEGF does, and take $\lambda_{T_{r} T_{\beta}}=5 \lambda_{T_{r} G}$. From the steady state of Eq. (5), we get, $\left(\lambda_{T_{r} T_{\beta}} \cdot \frac{1}{2}+\lambda_{T_{r} G} \cdot \frac{1}{2}\right) T_{10}-d_{T_{r}} T_{r}=0$, where $T_{10}=1 \times 10^{-3} \mathrm{~g} / \mathrm{cm}^{3}, T_{r}=K_{T_{r}}=5 \times 10^{-4} \mathrm{~g} / \mathrm{cm}^{3}$
[59], and $d_{T_{r}}=0.2 /$ day [59]. Hence $\lambda_{T_{r} G}=0.083 /$ day and $\lambda_{T_{r} T_{\beta}}=0.415 /$ day.

Eq. (6).

By [43], $d_{E}=0.69 /$ day, $E_{M}=5 \times 10^{-3} \mathrm{~g} / \mathrm{cm}^{3}, K_{E}=2.5 \times$ $10^{-3} \mathrm{~g} / \mathrm{cm}^{3}, G_{0}=3.65 \times 10^{-10}$. We take $E_{M}=2 K_{E}=$ $5 \times 10^{-3} \mathrm{~g} / \mathrm{cm}^{3}$. From the steady state of Eq. (6), we get $\lambda_{E}=2 d_{E} /\left(K_{G}-G_{0}\right)=1.98 \times 10^{7} \mathrm{~cm}^{3} / \mathrm{g} \cdot$ day. Assuming that the threshold $G_{0}$ (which was taken to be constant) is actually increasing with the progression of the cancer in the control case (no drugs), we increase $\lambda_{E}$, taking $\lambda_{E}=$ $2.77 \times 10^{7} \mathrm{~cm}^{3} / \mathrm{g} \cdot$ day in mice and $\lambda_{E}=2.08 \times 10^{7} \mathrm{~cm}^{3} / \mathrm{g}$. day in humans.

Eq. (7).

We take $d_{C}=0.17$ day $^{-1}, C_{M}=0.8 \mathrm{~g} / \mathrm{cm}^{3}$ [59] and $\lambda_{C W}=1.6 /$ day [60]. In the steady state of the control case (no drugs), we assume that $C$ is approximately $0.4 \mathrm{~g} / \mathrm{cm}^{3}$, and $W=W_{0}=K_{W}=1.69 \times 10^{-4} \mathrm{~g} / \mathrm{cm}^{3}$ (see the estimates for Eq. (11)). From the steady state of Eq. (7) in the control case we have,

$$
\frac{1}{2} \lambda_{C W} K_{W} / W_{0}-\eta_{1} K_{T_{1}}-\eta_{8} K_{T_{8}}-d_{C}=0,
$$

where $K_{T_{1}}=2 \times 10^{-3} \mathrm{~g} / \mathrm{cm}^{3}, K_{T_{8}}=1 \times 10^{-3} \mathrm{~g} / \mathrm{cm}^{3}$; we take $\eta_{8}=2 \eta_{1}$; hence $\eta_{8}=\left(\lambda_{C} K_{W} /\left(2 W_{0}\right)-d_{C}\right) /\left(2 K_{T_{8}}\right)=$ $60.375 \mathrm{~cm}^{3} / \mathrm{g} \cdot$ day and $\eta_{1}=30.19 \mathrm{~cm}^{3} / \mathrm{g} \cdot$ day. Since in the control case the tumor grows, we increase the growth rate of cancer cells taking $\lambda_{C W}=2.24 /$ day in mice and $\lambda_{C W}=1.76 /$ day in humans.

Eq. (10).

From the steady state of Eq. (10) we have, $\lambda_{T_{\beta} C} C+$ $\lambda_{T_{\beta} T_{r}} T_{r}=d_{T_{\beta}} T_{\beta}$, where $T_{r}=K_{T_{r}}=5 \times 10^{-4} \mathrm{~g} / \mathrm{cm}^{3}$, $C=K_{C}=0.4 \mathrm{~g} / \mathrm{cm}^{3}$, and, by [15], $T_{\beta}=K_{T_{\beta}}=$ $2.68 \times 10^{-13} \mathrm{~g} / \mathrm{cm}^{3}$ and $d_{T_{\beta}}=499.07 \mathrm{day}^{-1}$, and by [61], $\lambda_{T_{\beta} T_{r}}=5.57 \times 10^{-9} /$ day. Hence $\lambda_{T_{\beta} C}=3.27 \times 10^{-10} /$ day.

Eq. (11).

From steady state of Eq. (11) we get, $\lambda_{W E} E-d_{W} W=0$, where $\lambda_{W E}=7 \times 10^{-2} /$ day [43], $W=K_{W}=1.69 \times 10^{-4}$ $\mathrm{g} / \mathrm{cm}^{3}$ [43], $E=K_{E}=2.5 \times 10^{-3} \mathrm{~g} / \mathrm{cm}^{3}$. Hence, $d_{W}=$ $\lambda_{W E} E / W=1.04 /$ day.

Eq. (12).

From steady state of Eq. (12) we get, $\lambda_{G W} C-d_{G} G=0$, where $d_{G}=12.6 /$ day [43], $G=K_{G}=7 \times 10^{-8} \mathrm{~g} / \mathrm{cm}^{3}$ [43], $C=K_{C}=0.4 \mathrm{~g} / \mathrm{cm}^{3}$. Hence, $\lambda_{G W}=2.21 \times 10^{-6} /$ day.

Eqs. (13)-(17).

By [15], $\rho_{P}=2.49 \times 10^{-7}, \rho_{L}=5.22 \times 10^{-7}, \varepsilon_{T}=0.8$, $\varepsilon_{C}=0.01$. We assume that $\varepsilon_{G}=0.1 / K_{G}=1.43 \times 10^{6}$ $\mathrm{cm}^{3} / \mathrm{g}$. From Eqs. (13)-(16) we get, 


$$
\begin{aligned}
K_{P_{1}}=P_{1}= & \rho_{P}\left(T_{1}+\varepsilon_{T} T_{r}\right) \\
= & \left(2.49 \times 10^{-7}\right) \times\left[2 \times 10^{-3}+0.8 \times\left(5 \times 10^{-4}\right)\right] \\
= & 5.98 \times 10^{-10} \mathrm{~g} / \mathrm{cm}^{3}, \\
K_{P_{8}}=P_{8} & =\rho_{P} T_{8}\left(1+\varepsilon_{G} G\right) \\
& =\left(2.49 \times 10^{-7}\right) \times\left(1 \times 10^{-3}\right) \times(1+0.1) \\
& =2.74 \times 10^{-10} \mathrm{~g} / \mathrm{cm}^{3},
\end{aligned}
$$

and

$$
\begin{aligned}
K_{L}=L & =\rho_{L}\left(T_{1}+T_{8}+\varepsilon_{T} T_{r}+\varepsilon_{C} C\right) \\
& =\left(5.22 \times 10^{-7}\right) \times\left[3.4 \times 10^{-3}+0.01 \times 0.4\right] \\
& =3.86 \times 10^{-9} \mathrm{~g} / \mathrm{cm}^{3} .
\end{aligned}
$$

In steady state with $P=K_{P}=K_{P_{1}}+K_{P_{8}}, L=K_{L}$, $Q=K_{Q}$ and $G=K_{G}$ we have, by Eq. (17), $K_{Q}=\sigma K_{P} K_{L}$. We take $K_{T Q}=K_{Q}=\frac{1}{2} \sigma K_{P} K_{L}$. Hence, $Q / K_{T Q}=$ $P L /\left(\frac{1}{2} K_{P} K_{L}\right)$ and

$$
\frac{1}{1+Q / K_{T Q}}=\frac{1}{1+P L /\left(\frac{1}{2} K_{P} K_{L}\right)}=\frac{1}{1+P L / K_{T Q}^{\prime}},
$$

where $K_{T Q}^{\prime}=\frac{1}{2} K_{P} K_{L}=\frac{1}{2} \times$ $\left(5.98 \times 10^{-10}+2.74 \times 10^{-10}\right) \times\left(3.86 \times 10^{-9}\right)=$ $1.68 \times 10^{-18} \mathrm{~g}^{2} / \mathrm{cm}^{6}$.

Eqs. (18)-(19).

We take $d_{A}=0.34$ day $^{-1}$ and assume that $10 \%$ of $A$ is used in blocking PD-1, while the remaining 90\% degrades naturally. Hence,

$\mu_{A P}=\frac{d_{A}}{9 P}=\frac{0.34}{9 \times\left(8.715 \times 10^{-10}\right)}=4.33 \times 10^{7} \mathrm{~cm}^{3} / \mathrm{g} \cdot$ day.

Since the molecular mass of anti-PD-1 (32kDa [62]) approximates the molecular mass of PD-1 (20.5 - $40 \mathrm{kDa}$ [62]), we take $\mu_{P A}=\mu_{A P}=4.33 \times 10^{7} \mathrm{~cm}^{3} / \mathrm{g} \cdot$ day.

By [63], the half-life of anti-VEGF is 2.82-4.58 days; we take it to be 4 days, so that $d_{B}=\frac{\ln 2}{4}=0.17$ day $^{-1}$. We assume that $90 \%$ of $B$ is depleted in blocking of VEGF, while the remaining $10 \%$ degrades naturally. Hence,

$$
\mu_{B G}=\frac{9 d_{B}}{G}=\frac{9.17}{7 \times 10^{-8}}=2.19 \times 10^{7} \mathrm{~cm}^{3} / \mathrm{g} \cdot \text { day. }
$$

The molecular mass of anti-VEGF is approximately 6 times larger than that of VEGF, so we take $\mu_{G B}=6 \mu_{B G}=$ $1.31 \times 10^{8} \mathrm{~cm}^{3} / \mathrm{g} \cdot$ day.

\section{Computational method}

We employ a moving mesh method [48] to numerically solve the free boundary problem for the tumor proliferation model. To illustrate this method, we take Eq. (7) as an example and rewrite it in the following form:

$$
\frac{\partial C(r, t)}{\partial t}=\delta_{C} \Delta C(r, t)-\operatorname{div}(\mathbf{u} C)+F,
$$

where $F$ represents the term in the right hand side of Eq. (7). Let $r_{i}^{k}$ and $C_{i}^{k}$ denote numerical approximations of $\mathrm{i}$-th grid point and $C\left(r_{i}^{k}, n \tau\right)$, respectively, where $\tau$ is the size of the time-step. The discretization of Eq. (29) is derived by the fully implicit finite difference scheme:

$$
\begin{aligned}
\frac{C_{i}^{k+1}-C_{i}^{k}}{\tau}= & \delta_{C}\left(C_{r r}+\frac{2}{r_{i}^{k}} C_{r}\right)-\left(\frac{2}{r_{i}^{k+1}} u_{i}^{k+1}+u_{r}\right) C_{i}^{k+1} \\
& -u_{i}^{k+1} C_{r}+F_{i}^{k+1},
\end{aligned}
$$

where $C_{r}=\frac{h_{-1}^{2} C_{i+1}^{k+1}-h_{1}^{2} C_{i-1}^{k+1}-\left(h_{1}^{2}-h_{-1}^{2}\right) C_{i}^{k+1}}{h_{1}\left(h_{-1}^{2}-h_{1} h_{-1}\right)}, C_{r r}=$ $2 \frac{h_{-1} C_{i+1}^{k+1}-h_{1} C_{i-1}^{k+1}+\left(h_{1}-h_{-1}\right) C_{i}^{k+1}}{h_{1}\left(h_{1} h_{-1}-h_{-1}^{2}\right)}$,

$u_{r}=\frac{h_{-1}^{2} u_{i+1}^{k+1}-h_{1}^{2} u_{i-1}^{k+1}-\left(h_{1}^{2}-h_{-1}^{2}\right) u_{i}^{k+1}}{h_{1}\left(h_{-1}^{2}-h_{1} h_{-1}\right)}, h_{-1}=r_{i-1}^{k+1}-r_{i}^{k+1}$ and $h_{1}=r_{i+1}^{k+1}-r_{i}^{k+1}$. The mesh moves by $r_{i}^{k+1}=r_{i}^{k}+u_{i}^{k+1} \tau$, where $u_{i}^{k+1}$ is solved by the velocity equation. To deal with the different scales of the variables in the simulations, we first non-dimensionalized the model and then applied the above method.

\section{Acknowledgements}

This work is supported by the Mathematical Biosciences Institute and the National Science Foundation (DMS 0931642), and by the Renmin University of China and the National Natural Science Foundation of China (Grant No.

11501568), and the International Postdoctoral Exchange Fellowship Program 2016 by the Office of China Postdoctoral Council.

\section{Funding}

XL was supported by National Natural Science Foundation of China (Grant No. 11501568).

\section{Availability of data and materials}

The dataset supporting the conclusions of this article is included within the article.

\section{Authors' contributions}

$\mathrm{AF}$ and $\mathrm{XL}$ developed and simulated the model, and wrote the final manuscript. Both authors read and approved the final manuscript.

\section{Ethics approval and consent to participate}

Not applicable.

\section{Consent for publication}

Not applicable.

\section{Competing interests}

The authors declare that they have no competing interests.

\section{Publisher's Note}

Springer Nature remains neutral with regard to jurisdictional claims in published maps and institutional affiliations.

\section{Author details}

${ }^{1}$ Institute for Mathematical Sciences, Renmin University of China, Beijing, People's Republic of China. ${ }^{2}$ Mathematical Bioscience Institute \& Department of Mathematics, Ohio State University, Columbus, OH, USA.

Received: 26 January 2018 Accepted: 19 February 2019

Published online: 13 March 2019 


\section{References}

1. Meadows KL, Hurwitz HI. Anti-vegf therapies in the clinic. Cold Spring Harb Perspect Med. 2012;2(10):006577.

2. Nerini IF, Cesca M, Bizzaro F, Giavazzi R. Combination therapy in cancer: effects of angiogenesis inhibitors on drug pharmacokinetics and pharmacodynamics. Chin J Cancer. 2016;35(1):61.

3. Turley RS, Fontanella AN, Padussis JC, Toshimitsu H, Tokuhisa Y, Cho EH, Hanna G, Beasley GM, Augustine CK, Dewhirst MW, et al. Bevacizumab-induced alterations in vascular permeability and drug delivery: a novel approach to augment regional chemotherapy for in-transit melanoma. Clin Cancer Res. 2012;18(12):3328-39.

4. Pastuskovas CV, Mundo EE, Williams SP, NayakTK, Ho J, Ulufatu S, Clark S, Ross S, Cheng E, Parsons-Reponte K, et al. Effects of anti-vegf on pharmacokinetics, biodistribution, and tumor penetration of trastuzumab in a preclinical breast cancer model. Mol Cancer Ther. 2012;11(3):752-62.

5. Daldrup-Link HE, Okuhata Y, Wolfe A, Srivastav S, Øie S, Ferrara N, Cohen RL, Shames DM, Brasch RC. Decrease in tumor apparent permeability-surface area product to a mri macromolecular contrast medium following angiogenesis inhibition with correlations to cytotoxic drug accumulation. Microcirculation. 2004;11(5):387-96.

6. Cesca M, Morosi L, Berndt A, Nerini IF, Frapolli R, Richter P, Decio A, Dirsch O, Micotti E, Giordano S, et al. Bevacizumab-induced inhibition of angiogenesis promotes a more homogeneous intratumoral distribution of paclitaxel, improving the antitumor response. Mol Cancer Ther. 2016;15(1):125-35.

7. Kabbinavar F, Hurwitz HI, Fehrenbacher L, Meropol NJ, Novotny WF, Lieberman G, Griffing S, Bergsland E. Phase ii, randomized trial comparing bevacizumab plus fluorouracil (fu)/leucovorin (lv) with fu/lv alone in patients with metastatic colorectal cancer. J Clin Oncol. 2003;21(1):60-5.

8. Wildiers H, Guetens G, De Boeck G, Verbeken E, Landuyt B, Landuyt W, De Bruijn E, Van Oosterom A. Effect of antivascular endothelial growth factor treatment on the intratumoral uptake of cpt-11. Br J Cancer. 2003;88(12):1979.

9. Liu Y, Suzuki M, Masunaga S-i, Chen Y-W, Kashino G, Tanaka H, Sakurai Y, Kirihata M, Ono K. Effect of bevacizumab treatment on p-boronophenylalanine distribution in murine tumor. J Radiat Res. 2012;54(2):260-7.

10. Van der Veldt AA, Lubberink $M$, Bahce I, Walraven $M$, de Boer MP, Greuter HN, Hendrikse NH, Eriksson J, Windhorst AD, Postmus PE, et al. Rapid decrease in delivery of chemotherapy to tumors after anti-vegf therapy: implications for scheduling of anti-angiogenic drugs. Cancer Cell. 2012;21(1):82-91.

11. Maitland ML, Hudoba C, Snider KL, Ratain MJ. Analysis of the yield of phase ii combination therapy trials in medical oncology. Clin Cancer Res. 2010;16(21):5296-302.

12. Sharma MR, Stadler WM, Ratain MJ. Randomized phase ii trials: a long-term investment with promising returns. J Natl Cancer Inst. 2011;103(14):1093-100.

13. Paller CJ, Bradbury PA, Ivy SP, Seymour L, LoRusso PM, Baker L, Rubinstein L, Huang E, Collyar D, Groshen S, et al. Design of phase i combination trials: recommendations of the clinical trial design task force of the nci investigational drug steering committee. Clin Cancer Res. 2014;20(16):4210-7.

14. Lai X, Friedman A. Combination therapy of cancer with cancer vaccine and immune checkpoint inhibitor: A mathematical model. PLoS ONE. 2017:12(2):0178479.

15. Lai X, Friedman A. Combination therapy of cancer with braf inhibitor and immune checkpoint inhibitor: A mathematical model. BMC Syst Biol. 2017;11(70):1-18. https://doi.org/10.1186/s12918-017-0446-9.

16. Ohm JE, Gabrilovich DI, Sempowski GD, Kisseleva E, Parman KS, NadafS, Carbone DP. Vegf inhibits t-cell development and may contribute to tumor-induced immune suppression. Blood. 2003;101(12):4878-86.

17. Mulligan JK, Rosenzweig SA, Young MRI. Tumor secretion of vegf induces endothelial cells to suppress t cell functions through the production of pge2. J Immunother (Hagerstown, Md.: 1997). 2010;33(2):126-35.

18. Gavalas NG, Tsiatas M, Tsitsilonis O, Politi E, loannou K, Ziogas AC, Rodolakis A, Vlahos G, Thomakos N, Haidopoulos D, et al. Vegf directly suppresses activation of $\mathrm{t}$ cells from ascites secondary to ovarian cancer via vegf receptor type 2. Br J Cancer. 2012;107(11):1869-75.

19. Ziogas AC, Gavalas NG, Tsiatas M, Tsitsilonis O, Politi E, Terpos E, Rodolakis A, Vlahos G, Thomakos N, Haidopoulos D, et al. Vegf directly suppresses activation of t cells from ovarian cancer patients and healthy individuals via vegf receptor type 2. Int J Cancer. 2012;130(4):857-64.

20. Li Y-L, Zhao H, Ren X-B. Relationship of vegf/vegfr with immune and cancer cells: staggering or forward?. Cancer Biol Med. 2016;13(2):206-14.

21. Wallin JJ, Bendell JC, Funke R, Sznol M, Korski K, Jones S, Hernandez G, Mier J, He X, Hodi FS, et al. Atezolizumab in combination with bevacizumab enhances antigen-specific t-cell migration in metastatic renal cell carcinoma. Nat Commun. 2016;7:12624.

22. Kuusk T, Albiges L, Escudier B, Grivas N, Haanen J, Powles T, Bex A. Antiangiogenic therapy combined with immune checkpoint blockade in renal cancer. Angiogenesis. 2017;20(2):205-215.

23. Ott PA, Hodi FS, Buchbinder El. Inhibition of immune checkpoints and vascular endothelial growth factor as combination therapy for metastatic melanoma: an overview of rationale, preclinical evidence, and initial clinical data. Front Oncol. 2015;5(202):1-7.

24. Einstein DJ, McDermott DF. Combined blockade of vascular endothelial growth factor and programmed death 1 pathways in advanced kidney cancer. Clin Adv Hematol Oncol. 2017;15(6):478-88.

25. Alfaro C, Suarez N, Gonzalez A, Solano S, Erro L, Dubrot J, Palazon A, Hervas-Stubbs S, Gurpide A, Lopez-Picazo JM, et al. Influence of bevacizumab, sunitinib and sorafenib as single agents or in combination on the inhibitory effects of vegf on human dendritic cell differentiation from monocytes. Br J Cancer. 2009;100(7):1111-9.

26. Gabrilovich DI, Chen HL, Girgis KR, Cunningham HT, Meny GM, Nadaf S, Kavanaugh D, Carbone DP. Production of vascular endothelial growth factor by human tumors inhibits the functional maturation of dendritic cells. Nat Med. 1996;2(10):1096-103.

27. Voron T, Colussi O, Marcheteau E, Pernot S, Nizard M, Pointet A-L, Latreche S, Bergaya S, Benhamouda N, Tanchot C, et al. Vegf-a modulates expression of inhibitory checkpoints on cd8+t cells in tumors. J Exp Med. 2015;212(2):139-48.

28. Terme M, Pernot S, Marcheteau E, Sandoval F, Benhamouda N, Colussi O, Dubreuil O, Carpentier AF, Tartour E, Taieb J. Vegfa-vegfr pathway blockade inhibits tumor-induced regulatory t-cell proliferation in colorectal cancer. Cancer Res. 2013;73(2):539-49.

29. Yasuda S, Sho M, Yamato I, Yoshiji H, Wakatsuki K, Nishiwada S, Yagita H, Nakajima Y. Simultaneous blockade of programmed death 1 and vascular endothelial growth factor receptor 2 (vegfr2) induces synergistic anti-tumour effect in vivo. Clin Exp Immunol. 2013;172(3):500-6.

30. Sims GP, Rowe DC, Rietdijk ST, Herbst R, Coyle AJ. Hmgb1 and rage in inflammation and cancer. Annu Rev Immunol. 2010;28:367-88.

31. Zandarashvili L, Sahu D, Lee K, Lee YS, Singh P, Rajarathnam K, et al. Real-time kinetics of high-mobility group box 1 (hmgb1) oxidation in extracellular fluids studied by in situ protein $\mathrm{nmr}$ spectroscopy. J Biol Chem. 2013;288(17):11621-7.

32. Palucka J, Banchereau J. Cancer immunotherapy via dendritic cells. Nat Rev Cancer. 2012;12(4):265-77.

33. Saenz R, Futalan D, Leutenez L, Eekhout F, Fecteau JF, Sundelius S, et al. Tlr4-dependent activation of dendritic cells by an hmgb1-derived peptide adjuvant. J Transl Med. 2014;12(211):1-11.

34. Janco JMT, Lamichhane P, Karyampudi L, Knutson KL. Tumor-infiltrating dendritic cells in cancer pathogenesis. J Immunol. 2015;194(7):2985-91.

35. Ma Y, Shurin1 GV, Peiyuan Z, Shurin MR. Dendritic cells in the cancer microenvironment. J Cancer. 2013;4(1):36-44.

36. Perrot CY, Javelaud D, Mauviel A. Insights into the transforming growth factor-beta signaling pathway in cutaneous melanoma. Ann Dermatol. 2013;25(2):135-44.

37. Whiteside TL. The role of regulatory t cells in cancer immunology. Immunotargets Ther. 2015:4:159-71.

38. Shi L, Chen S, Yang L, Li Y. The role of pd-1 and pd-11 in t-cell immune suppression in patients with hematological malignancies. J Hematol Oncol. 2013;6(74):10-118617568722674.

39. Muppidi MR, George S. Immune checkpoint inhibitors in renal cell carcinoma. J Target Ther Cancer 2015. 2015;4:47-52.

40. Umansky V, Blattner C, Gebhardt C, Utikal J. The role of myeloid-derived suppressor cells (mdsc) in cancer progression. Vaccines. 2016;4(36):1-16.

41. Szomolay B, Eubank TD, Roberts RD, Marsh CB, Friedman A. Modeling the inhibition of breast cancer growth by gm-csf. J Theor Biol. 2012;303: $141-151$.

42. Chanmee T, Ontong P, Konno K, Itano N. Tumor-associated macrophages as major players in the tumor microenvironment. Cancers. 2014;6(3):1670-90. 
43. Hao W, Friedman A. Serum upar as biomarker in breast cancer recurrence: A mathematical model. PLoS ONE. 2016;11(4):0153508.

44. Chen D, Roda JM, Marsh CB, Eubank TD, Friedman A. Hypoxia inducible factors-mediated inhibition of cancer by gm-csf: a mathematical model. Bull Math Biol. 2012;74(11):2752-77.

45. Cheng X, Veverka V, Radhakrishnan A, Waters LC, Muskett FW, Morgan SH, et al. Human pd-I1/b7-h1/cd274 protein. Sino Biological Inc. http://www. sinobiological.com/PD-L1-B7-H1-CD274-Protein-g-533.html.

46. Francisco LM, Sage PT, Sharpe AH. The pd-1 pathway in tolerance and autoimmunity. Immunol Rev. 2010;236:219-42.

47. Mautea RL, Gordona SR, Mayere AT, McCrackena MN, Natarajane A, Ring NG, et al. Engineering high-affinity pd-1 variants for optimized immunotherapy and immuno-pet imaging. Proc Natl Acad Sci USA. 2015;112(47):6506-14.

48. D'Acunto B. Computational Methods for PDE in Mechanics. Series on Advances in Mathematics for Applied Sciences-Vol.67. Singapore: Word Scientific; 2004.

49. Marino S, Hogue I, Ray C, Kirschner D. A methodology for performing global uncertainty and sensitivity analysis in systems biology. J Theor Biol. 2008;254(1):178-96.

50. W. Humphrey R, M Brockway-Lunardi L, T Bonk D, Dohoney KM, Doroshow JH, Meech SJ, Ratain MJ, Topalian SL, M Pardoll D. Opportunities and challenges in the development of experimental drug combinations for cancer. J Natl Cancer Inst. 2011;103(16):1222-6.

51. Miles D, von Minckwitz G, Seidman AD. Combination versus sequential single-agent therapy in metastatic breast cancer. Oncologist. 2002;7(Supplement 6):13-9.

52. Fujimoto-Ouchi K, Tanaka Y, Tominaga T. Schedule dependency of antitumor activity in combination therapy with capecitabine/5?-deoxy-5-fluorouridine and docetaxel in breast cancer models. Clin Cancer Res. 2001;7(4):1079-86.

53. Frei III E, Eder JP. Principles of dose, schedule, and combination therapy. Cancer Med. 2003;7:590-9.

54. Cabibbo G, Tremosini S, Galati G, Mazza G, Gadaleta-Caldarola G, Lombardi G, Antonucci M, Sacco R. Transarterial chemoembolization and sorafenib in hepatocellular carcinoma. Expert Rev Anticancer Ther. 2014;14(7):831-45.

55. Young ME. Estimation of diffusion coefficients of proteins. Biotech Bioeng. 1980;XXII:947-55.

56. Shui YB, Wang X, Hu JS, Wang SP, Garcia CM, et al. Vascular endothelial growth factor expression and signaling in the lens. Invest Ophthalmol Vis Sci. 2003;44(9):3911-9.

57. Liao KL, Bai XF, Friedman A. Mathematical modeling of interleukin-27 induction of anti-tumor t cells response. PLOS ONE. 2014;9(3):91844.

58. Androjna C, Gatica JE, Belovich JM, Derwin KA. Oxygen diffusion through natural extracellular matrices: implications for estimating critical thickness values in tendon tissue engineering. Tissue Eng A. 2008;14(4):559-69.

59. Friedman A, Hao W. The role of exosomes in pancreatic cancer microenvironment. Bull Math Biol. 2017;80(5):1111-113.

60. Chen D, Bobko AA, Gross AC, Evans R, Marsh CB, Khramtsov W, et al. Involvement of tumor macrophage hifs in chemotherapy effectiveness: mathematical modeling of oxygen, ph, and glutathione. PLOS ONE. 2014;9(10):107511.

61. Lo W.-C, Arsenescu V, Arsenescu RI, Friedman A. Inflammatory bowel disease: How effective is tnf-alpha suppression?. PLoS One. 2016;11(11): 0165782.

62. Abcam/. Anti-pd1 antibody (ab89828). http://www.abcam.com/pd1antibody-ab89828.html.

63. Agrawal S, Joshi M, Christoforidis JB. Vitreous inflammation associated with intravitreal anti-vegf pharmacotherapy. Mediat Inflamm. 2013;2013(943409):1-6

64. Kim Y, Lawler S, Nowicki MO, Chiocca EA, Friedman A. A mathematical model for pattern formation of glioma cells outside the tumor spheroid core. J Theor Biol. 2009;260(3):359-71.

65. Kim Y, Wallace J, Li F, Ostrowski M, Friedman A. Transformed epithelial cells and fibroblasts/myofibroblasts interaction in breast tumor: a mathematical model and experiments. J Theor Biol. 2010;61(3):401-21.

\section{Ready to submit your research? Choose BMC and benefit from:}

- fast, convenient online submission

- thorough peer review by experienced researchers in your field

- rapid publication on acceptance

- support for research data, including large and complex data types

- gold Open Access which fosters wider collaboration and increased citations

- maximum visibility for your research: over $100 \mathrm{M}$ website views per year

At $\mathrm{BMC}$, research is always in progress.

Learn more biomedcentral.com/submissions 